Review Article

\title{
Cold-Sprayed Metal Coatings with Nanostructure
}

\author{
Shuo Yin $\mathbb{D}^{1},{ }^{1}$ Chaoyue Chen, ${ }^{2}$ Xinkun Suo $\mathbb{D}^{3},{ }^{3}$ and Rocco Lupoi $\mathbb{D}^{1}$ \\ ${ }^{1}$ Department of Mechanical and Manufacturing Engineering, Trinity College Dublin, The University of Dublin, Parsons Building, \\ Dublin 2, Ireland \\ ${ }^{2}$ ICB UMR 6303, CNRS, Univ. Bourgogne Franche-Comté, UTBM, 90010 Belfort, France \\ ${ }^{3}$ Key Laboratory of Marine Materials and Related Technologies, Ningbo Institute of Materials Technology and Engineering, \\ Chinese Academy of Sciences, Ningbo 315201, China
}

Correspondence should be addressed to Shuo Yin; yins@tcd.ie; Xinkun Suo; suoxinkun@nimte.ac.cn and Rocco Lupoi; lupoir@tcd.ie

Received 4 November 2017; Revised 15 January 2018; Accepted 20 March 2018; Published 20 May 2018

Academic Editor: Federica Bondioli

Copyright $\odot 2018$ Shuo Yin et al. This is an open access article distributed under the Creative Commons Attribution License, which permits unrestricted use, distribution, and reproduction in any medium, provided the original work is properly cited.

Cold spray is a solid-state coating deposition technology developed in the 1980s. In comparison with conventional thermal spray processes, cold spray can retain the original properties of feedstock, prevent the adverse influence on the underlying substrate materials, and produce very thick coatings. Coatings with nanostructure offer the potential for significant improvements in physical and mechanical properties as compared with conventional non-nanostructured coatings. Cold spray has also demonstrated great capability to produce coatings with nanostructure. This paper is aimed at providing a comprehensive overview of cold-sprayed metal coatings with nanostructure. A brief introduction of the cold spray technology is provided first. The nanocrystallization phenomenon in the conventional cold-sprayed metal coatings is then addressed. Thereafter, focus is switched to the microstructure and properties of the cold-sprayed nanocrystalline metal coatings, and the cold-sprayed nanomaterialreinforced metal matrix composite (MMC) coatings. At the end, summary and future perspectives of the cold spray technology in producing metal coatings with nanostructure are concluded.

\section{Introduction}

Cold spray as an emerging coating technique has been developed for decades since its discovery in the 1980s [1]. In this process, powders are accelerated by the supersonic driving gas passing through a convergent-divergent nozzle and impacting onto a substrate at a very high velocity as schematized in Figure 1. Intensive plastic deformation induced by the high-velocity impact occurs in a cold sprayed particle, substrate (or already deposited coating), or both, enabling a low-oxidized cold-sprayed coating to be formed. Metals, metal matrix composites (MMCs), and even pure ceramics are able to deposit onto similar or dissimilar substrates with cold spray [2-4]. Unlike in conventional thermal spray, the feedstock used for cold spray remains solid state during the deposition process without any melting because of the relatively low temperature of the driving gas. Therefore, the inevitable defects emerging in the thermal-sprayed coating, for example, oxidation, thermal residual stress, and phase transformation, can be considerably avoided in the cold-sprayed coating [5]. Besides, the coating growth is almost unlimited for most metals and MMCs, which allows cold spray to act as an additive manufacturing technique for fabricating bulk materials $[6,7]$.

As a low-temperature deposition technology, cold spray is primarily applied for producing metal-based coatings. In general, particle velocity prior to the impact is an important factor for cold spray because the successful deposition of cold-sprayed particles relies only on the kinetic energy rather than the combined effect of both kinetic and thermal energies available in conventional thermal spraying. It has been widely accepted that there exists a unique critical velocity for a given condition (e.g., specific particle size, temperature, and material properties), above which successful bonding can be achieved [8-10]. Therefore, the feedstock powders for cold spray must have a proper size range (normally between 10 and $100 \mu \mathrm{m}$ ) to achieve a high particle impact velocity $[11,12]$. Nanoparticles, due to their low weights, are difficult 


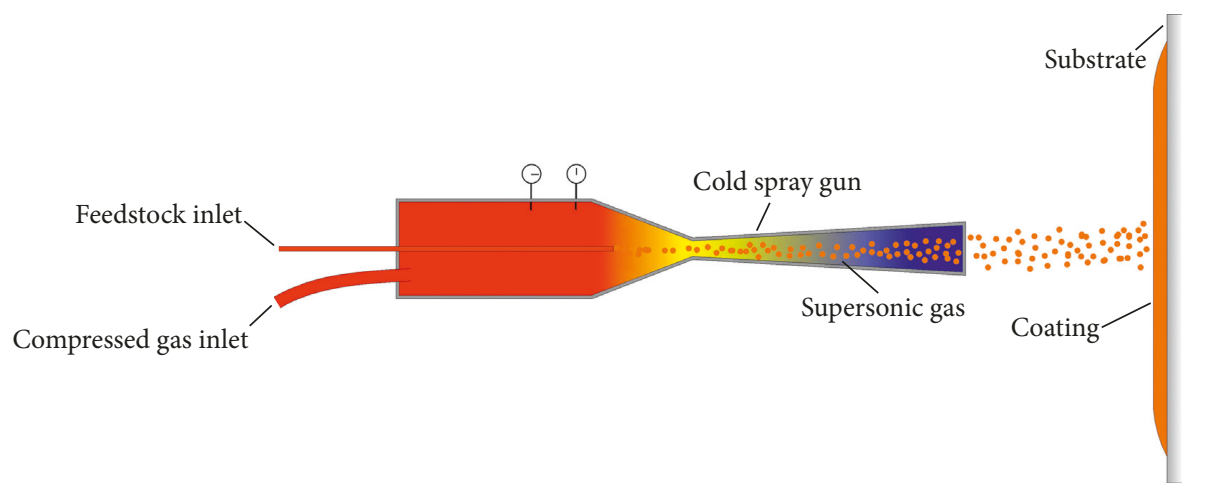

FIgURE 1: Schematic of the cold spray process.

to deposit on the substrate via cold spray. They are easy to be picked up by the driving gas and thereby suffer from dramatic deceleration when passing through the compressed bow-shock in front of the substrate [13]. Consequently, the impact velocity of nanoparticles is very low so that coating is hard to form on the substrate.

It is known that nanostructured materials generally have improved properties as compared with conventional materials [14]. Therefore, it is of importance for cold spray to gain the capability to produce coatings with nanostructure. Fortunately, although nanoparticles cannot be deposited directly by cold spray, cold-sprayed metal coatings can still exhibit nanostructure. Firstly, nanocrystallization in the form of grain refinement always occurs at the interparticle and coatingsubstrate interfacial regions during the deposition process due to the dynamic recrystallization, which can result in nanostructured grains within the cold-sprayed coating $[10,15-21]$. Secondly, the starting feedstock for cold spray can be nanocrystalline powders [14, 22-31]; in this case, the coating retains the nanostructure of the starting powders. Thirdly, using nanomaterials to reinforce MMC coatings can also make the coating to present nanostructure [32-50]. Up till now, a large number of studies have been done to study the cold sprayed coatings with nanostructure. However, a systematic review of these studies still lacks. Therefore, this paper aims to provide an overview of the metal coatings with nanostructure produced by cold spray, particularly focusing on the coating microstructure and properties. The nanocrystallization phenomenon in the cold-sprayed metal coatings is addressed first. Thereafter, the microstructure and properties of the cold-sprayed nanocrystalline metal coatings are discussed. Then, focus is switched to review the cold-sprayed nanomaterial-reinforced MMC coatings. According to the dimensions of the reinforcements, the MMC coatings were classified as $1 \mathrm{D}$ material-reinforced, 2D material-reinforced, and 3D material-reinforced MMC coatings. The final part of this paper is a summary and further perspective of the cold spray technology in the fabrication of metal coatings with nanostructure.

\section{Nanocrystallization in Cold-Sprayed Metal Coating}

2.1. Nanocrystallization Phenomenon. During cold spray process, metal particles experience intensive plastic deformation

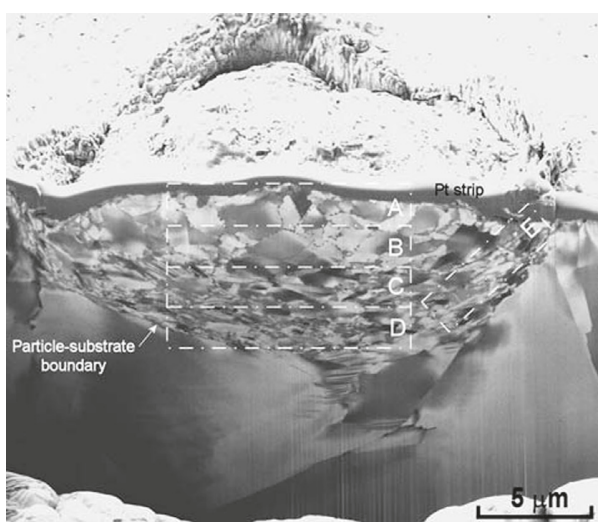

FIGURE 2: FIB-SEM imaging of the cross section of a $\mathrm{Cu}$ particle depositing onto a $\mathrm{Cu}$ substrate [17].

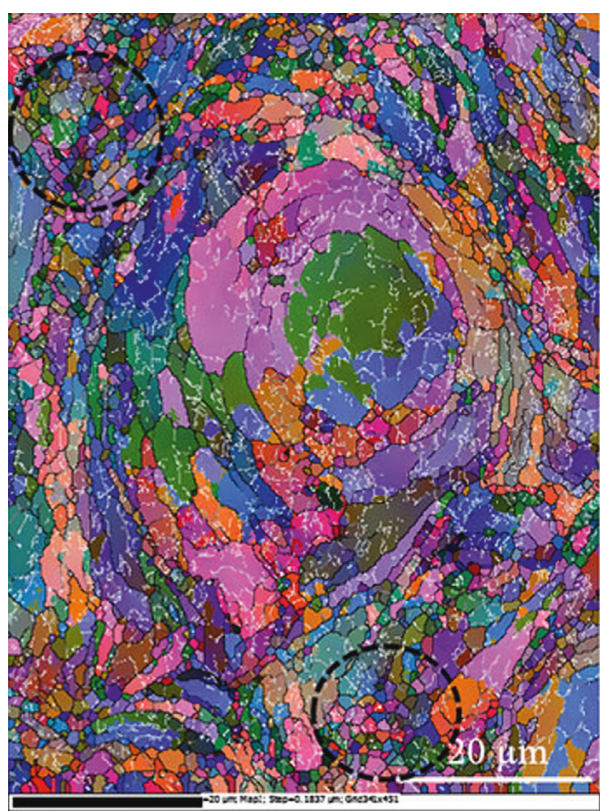

FIGURE 3: Euler angle EBSD patterns of the cross section of an $\mathrm{Al}$ 6061 particle in the cold-sprayed coating [18].

at the interparticle and coating-substrate interfacial regions due to the high-velocity impact. At highly deformed jetting areas, adiabatic shear instability takes place, which results in a significant temperature rise [51]. These rapid physical and 


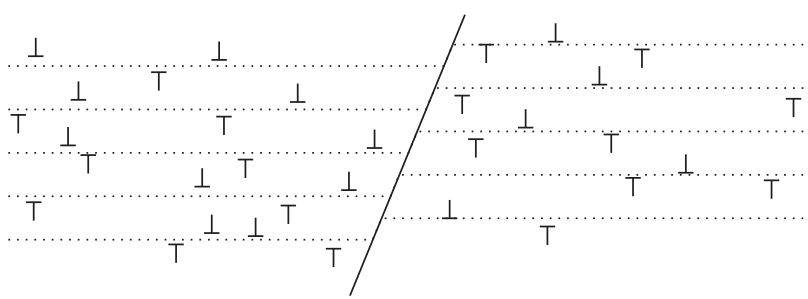

(a)

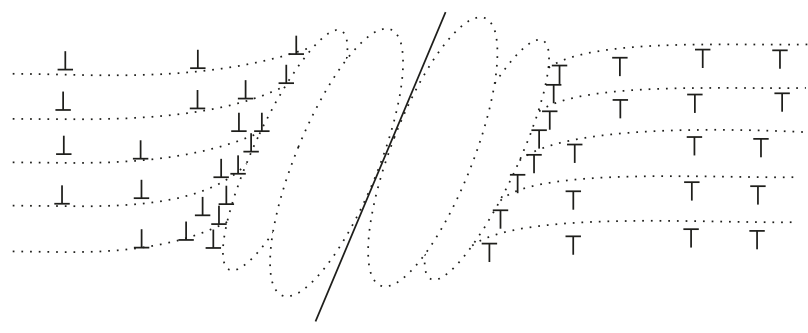

(c)

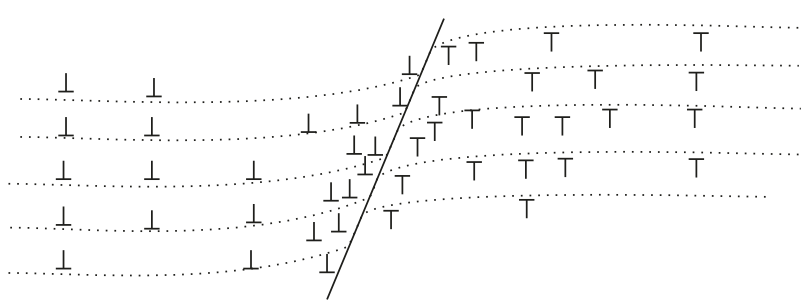

(b)

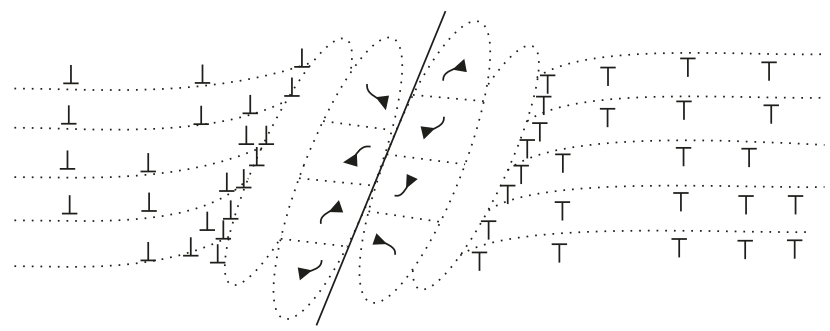

(d)

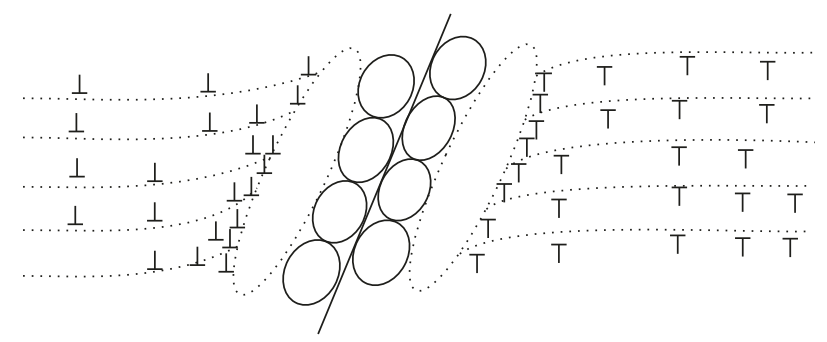

(e)

Figure 4: Schematic of the subgrains and ultrafine grain formation mechanism [20].

chemical changes work together, leading to the nanocrystallization of metal particles in the form of grain refinement $[10,15,16]$. Figure 2 shows the FIB-SEM imaging of the cross section of a $\mathrm{Cu}$ particle depositing onto a $\mathrm{Cu}$ substrate [17]. Clearly, particle grain structures showed an obvious change from the particle top surface towards the bottom, and such change was much dependent on the plastic deformation level. Based on the deformation level and grain size, the particle can be divided into three areas. The grains in the "A and B" areas had a large size because the top and inner parts of the particle did not experience too much plastic deformation. At the " $\mathrm{C}$ and D" areas, material underwent extensive high-strain/strain-rate plastic deformation; grains were highly deformed and elongated to subgrains. Particularly, at the peripheral "E" area where localized adiabatic shear instability took place, grains were significantly refined to ultrafine grains. Figure 3 shows the EBSD imaging of the cross section of an $\mathrm{Al} 6061$ particle in the cold-sprayed coating, providing a clearer view of different regions [18]. Note that the cross section was perpendicular to the particle impact direction. As can be seen, in the center of the particle, grain size was much larger as compared with the surrounding area. Adjacent to the central zone, elongated subgrains can be clearly observed. At the far surrounding region, ultrafine grains marked by black dotted circle can be noticed. This microstructure is quite similar to the $\mathrm{Cu}$ particle grain structure as shown in Figure 2, which demonstrates the universality of the nanocrystallization of the cold-sprayed metal particles after deposition.
2.2. Nanocrystallization Formation Mechanism. In order to explain the substantial reason behind the nanocrystallization phenomenon, Figure 4 shows the schematic of the subgrains and equiaxed ultrafine grain formation mechanism [20]. At the beginning, the large grain of the original particle contains uniformly distributed low-density dislocations (Figure 4(a)). When the particle starts to plastically deform upon impact, dislocation multiplication takes place and the dislocation density begins to increase at highly deformed zone (Figure 4(b)). As the deformation continues, the accumulated dislocations produce a number of dislocation cells, forming the elongated subgrains (Figure 4(c)). The TEM imaging in Figure 5 shows some elongated subgrains in a cold-sprayed Al 7075 particle after deposition [52]. Following the formation of subgrains, adiabatic shear instability happens at extreme deformation areas, resulting in a rapid temperature rise to a value higher than recrystallization temperature. Plastic deformation and heating then work together to induce the dynamic recrystallization at these areas $[15,17,18,53,54]$. Basically, dynamic recrystallization is controlled by two mechanisms: rotational and migrational types $[16,19,20]$. In terms of the cold-sprayed particles, rotation has been found to be the dominant mechanism for the occurrence of dynamics recrystallization [20,55]. Under the rotational dynamic recrystallization, elongated subgrains are further divided into equiaxed subgrains due to the increased dislocation density (Figure 4(d)). These equiaxed subgrains are rotated by additional shear forces to form the 


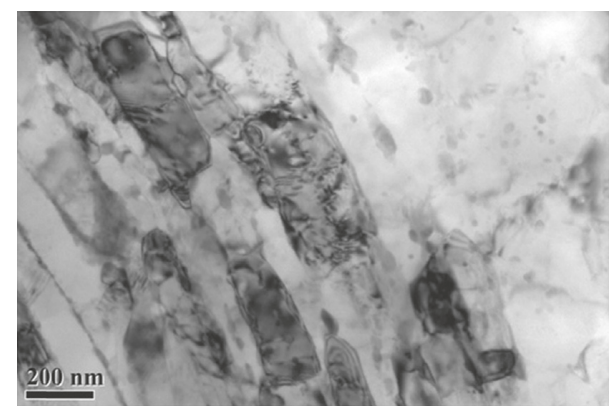

FIGURE 5: TEM imaging of elongated subgrains in a cold-sprayed Al 7075 particle [52].

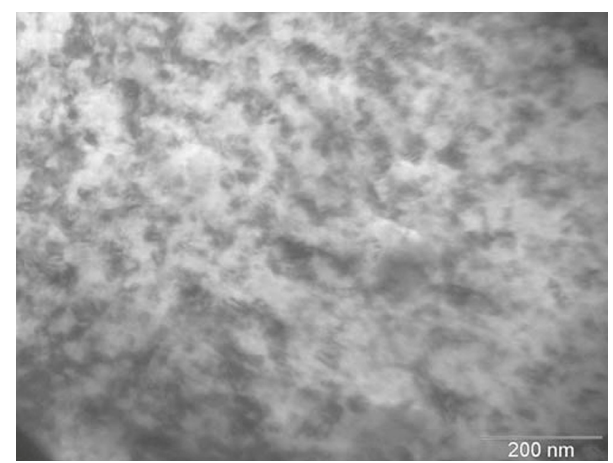

FIGURE 6: TEM imaging of cold-sprayed nanocrystalline Al 2018 coating [23].

ultrafine grains (Figure 4(e)) [16, 20]. Due to the increased dislocations and grain boundaries, the nanohardness and strength at these refined areas are higher as compared to at the other areas $[14,21]$.

\section{Nanocrystalline Metal Coatings via Cold Spray}

Nanocrystalline metals are polycrystalline metals with a crystallite size of a few nanometers (normally smaller than $100 \mathrm{~nm}$ ). They generally exhibit increased strength and hardness, improved toughness, reduced elastic modulus and ductility, enhanced diffusivity, higher specific heat, enhanced thermal expansion coefficient, and superior soft magnetic properties in comparison with conventional polycrystalline metals [56]. Cold spray, due to its low working temperature, has been found to be a robust tool to produce nanocrystalline metal coatings because nanocrystalline structure can be well retained in the coating after deposition. As an evidence, Figure 6 shows a TEM imaging of nanocrystalline Al 2018 coating produced via cold spray, where nanocrystalline grains can be clearly observed in the coating [23].

Preparation of nanocrystalline powders is one of the most important steps in the coating fabrication process. Mechanical ball milling is regarded as a simple, effective, and efficient method to produce nanocrystalline powders with a grain size as small as $20 \mathrm{~nm}$ or below [57]. It is a process where mixed powders are placed in a chamber and subjected to high-energy collision of balls to induce mechanical alloying. So far, various nanocrystalline powders have been produced through mechanical ball milling for cold spray [14, 22-31]. Table 1 summarizes the nanocrystalline powders produced for cold spray and their milling conditions.

Due to the increase of grain boundaries, the nanocrystalline powder hardness was normally much higher than the conventional counterpart, which makes the nanocrystalline coating to be harder but more porous as compared to the conventional coating $[23,29,30]$. For the same reason, the work hardening effect in the nanocrystalline coatings was not as prominent as in the conventional coatings $[23,25]$. Figure 7 shows a comparison of crosssectional microstructure between conventional and nanocrystalline $\mathrm{Al}$ coatings produced under the same working parameters [23]. It is seen that nanocrystalline coating had higher porosity than conventional coating due to the lack of sufficient plastic deformation. However, the coating hardness showed an opposite trend; nanocrystalline coating had a hardness of $4.41 \mathrm{GPa}$ which was higher than the hardness of conventional coating (3.75 GPa).

In terms of the mechanical properties, cold-sprayed nanocrystalline coatings have shown better wear-resistance performance than conventional coatings as a result of higher hardness [29]. However, due to the simultaneous higher porosity, fatigue strength was found to not improve significantly [30]. So far, the property investigation of cold-sprayed nanocrystalline coatings is still very limited; for example, investigations on coating cohesion strength are still lacking. Considering the unique advantages of hard nanocrystalline coatings, more mechanical property tests such as coating tensile stress and elongation are encouraged in the future work.

\section{1D Material-Reinforced MMC Coatings via Cold Spray}

Carbon nanotube (CNT) is an allotrope of carbon with a cylindrical nanostructure. The diameter of CNT can be as small as $1 \mathrm{~nm}$ but the length can be up to several centimeters; thus, CNT is also recognized as $1 \mathrm{D}$ nanomaterial. As a member of carbon family, CNT has extraordinary thermal conductivity, electrical, and mechanical properties. These novel properties make CNT potentially valuable and useful in a wide variety of applications in nanotechnology, electronics, optics, thermal engineering, and other fields of material science [58]. Due to the $1 \mathrm{D}$ nanostructure, CNT cannot exist in the form of bulk state. Thereby, it is widely employed as reinforcements for improving the properties of pure metals. Currently, CNT-reinforced MMCs are mainly produced by powder metallurgy $[59,60]$ and thermal spray technologies $[61,62]$. These processes generally require high temperature to melt the binder phase, resulting in damage and phase transformation of CNT during fabrication [63, 64]. Cold spray, due to its low working temperature, has been applied to produce CNT-reinforced MMC coatings in recent years.

A number of investigations have proved that dense and thick CNT-reinforced MMC coatings can be fabricated via cold spray [41-44]. Among all these works, mechanical ball 
TABLE 1: Nanocrystalline powders for cold spray and the milling conditions [14, 22-31].

\begin{tabular}{|c|c|c|c|c|c|}
\hline Materials & Milling time (h) & Speed (rpm) & Ball diameter $(\mathrm{mm})$ & $\mathrm{BPR}$ & Control agent \\
\hline $\mathrm{Al}$ alloy 2009 & 10 & 200 & 6.4 & $20: 1$ & Liquid nitrogen \\
\hline $\mathrm{Al}$ alloy 2618 & 8 & 180 & 6.4 & $32: 1$ & Liquid nitrogen \\
\hline $\mathrm{Al}$ alloy 5083 & 8 & 180 & 6.4 & $32: 1$ & Liquid nitrogen \\
\hline $\mathrm{Al}$ alloy 7075 & N/A & 180 & 11.6 & $32: 1$ & Stearic acid \\
\hline Al-Mg alloy & 8 & 180 & 6.4 & $32: 1$ & Liquid nitrogen \\
\hline $\mathrm{Ni}$ & 15 & 180 & 6.4 & $30: 1$ & Liquid nitrogen \\
\hline $\mathrm{Ni}-\mathrm{Ti}$ alloy & $48,1 / 2 \mathrm{~h}$ rest per $\mathrm{h}$ & 400 & 20 & $13: 4$ & Alcohol \\
\hline $\mathrm{Ni}-20 \mathrm{Cr}$ alloy & $20,1 / 3 \mathrm{~h}$ rest per $\mathrm{h}$ & 300 & N/A & $10: 2$ & Toluene \\
\hline $\mathrm{Cu}$ & 12 & 200 & 6.4 & $30: 1$ & Liquid nitrogen \\
\hline
\end{tabular}

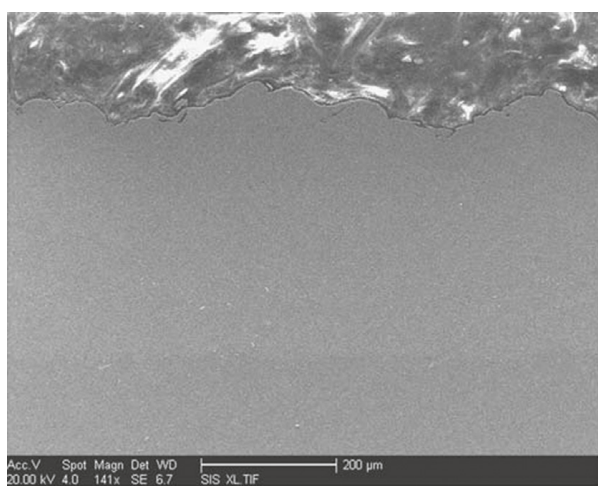

(a)

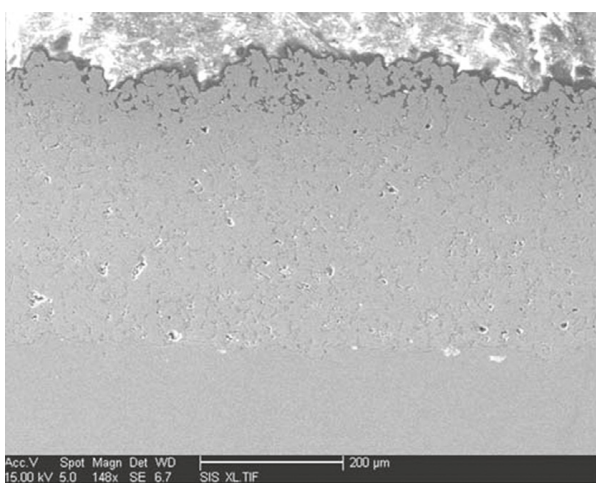

(c)

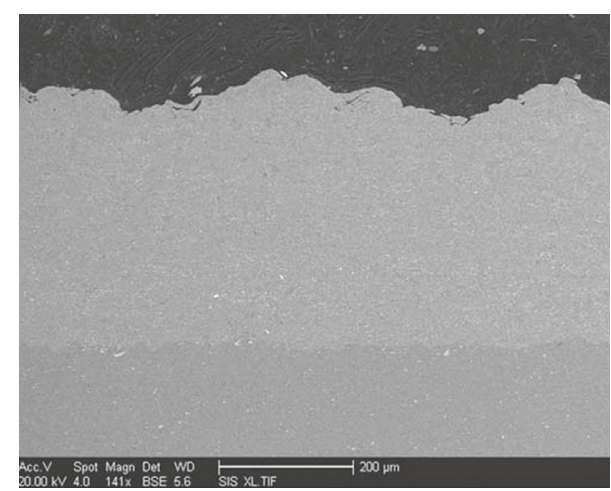

(b)

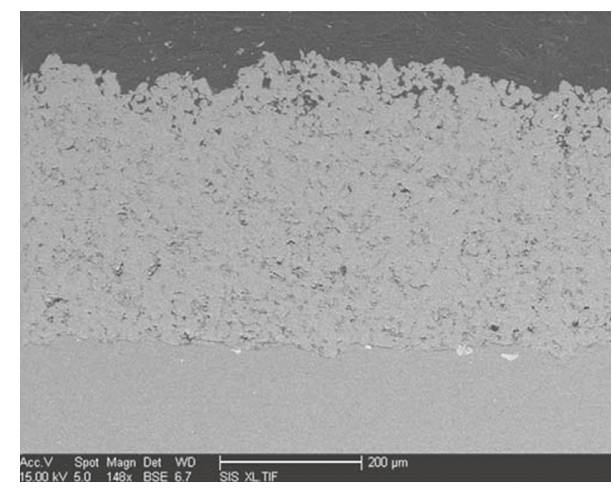

(d)

Figure 7: Comparison of the microstructure between cold-sprayed conventional and nanocrystalline Al coatings produced under same working parameters: (a) secondary electron imaging of conventional coating, (b) backscattered electron imaging of conventional coating, (c) secondary electron imaging of nanocrystalline coating, and (d) backscattered electron imaging of nanocrystalline coating [23].

milling as a robust technology was prevailingly used to prepare CNT-reinforced MMC powders. Figure 8 shows the cross-sectional view and EDX mapping of a ball-milled CNT-Cu MMC powder. As can be seen, CNT was successfully incorporated into the MMC powder and exhibited a homogenous distribution [41]. Following the preparation of the MMC powders, various CNT-reinforced MMC coatings were fabricated as listed in Table 2 [41-44, 65-68]. As an example, Figure 9 shows the TEM imaging of a coldsprayed CNT-Cu MMC produced by low-pressure cold spray [65]. Clearly, CNT was successfully involved in the cold-sprayed $\mathrm{Cu}$-based MMC coatings.

Although mechanical ball milling is promising for producing CNT-reinforced MMC powders, it also brings negative aspects. CNT reinforcements suffered from damage during the milling process due to the plastic deformation of the binder phase [65]. In addition, the high-velocity impact happening during the coating deposition process also led to the fracture of CNT $[44,65]$. Figure 10 shows the TEM imaging of damaged CNT in the cold-sprayed CNT-Cu coatings [44]. Two different damaging features can be noticed, which are impact-induced and shear-induced damages, respectively. The impact-induced damage was present in the form of a systematic fracture of the concentric tubes which progresses inward until the innermost tube has broken, while the shear-induced damage was featured uneven or asymmetric with respect to the tube axis [44]. Currently, prevention of damage of CNT during ball milling process is still a challenging work, which may be a research focus in the future work. 

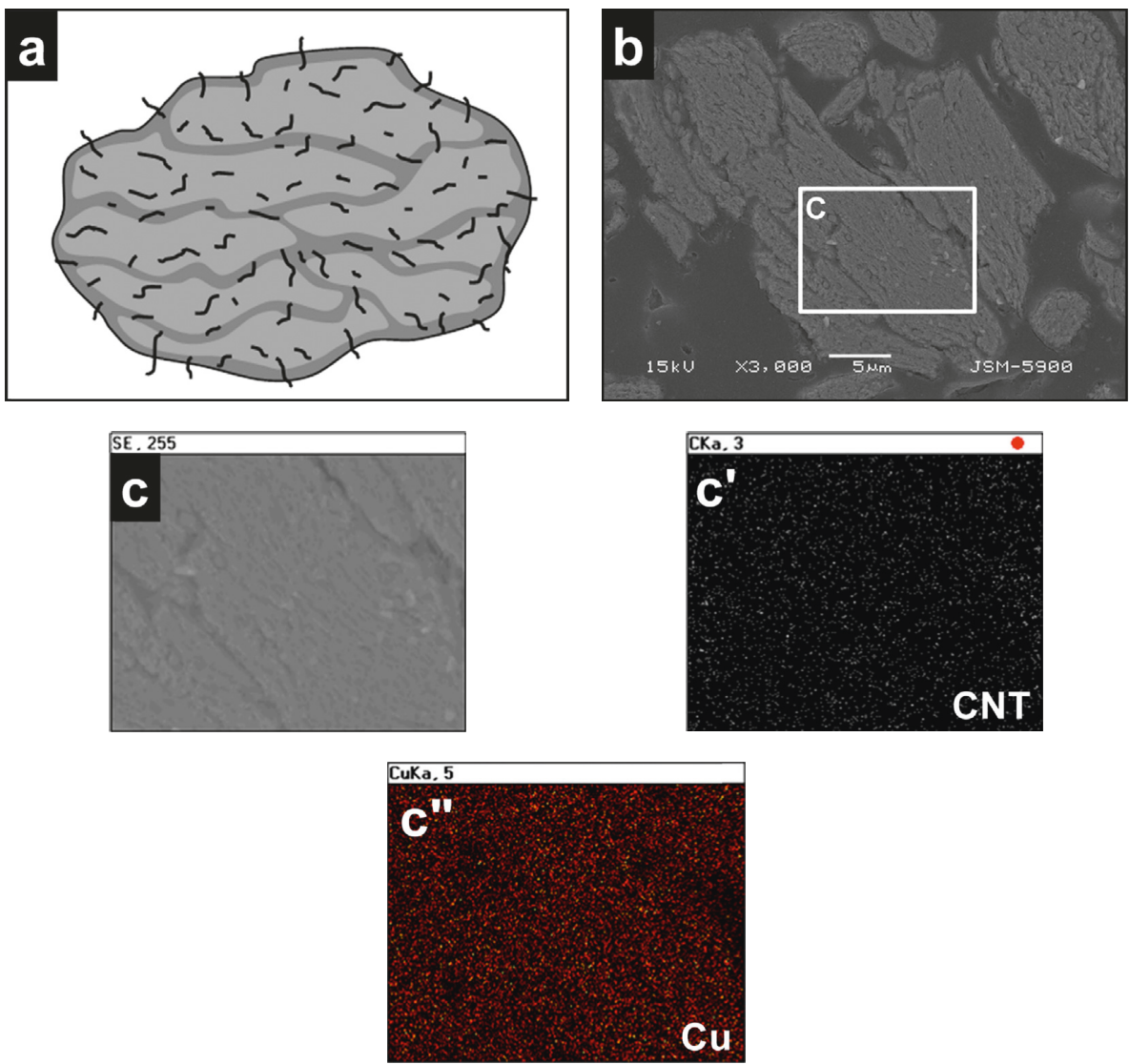

FIgURE 8: Cross-sectional view and EDX mapping of a ball-milled CNT-Cu MMC powder [41].

TABLE 2: CNT-reinforced MMC coatings produced by cold spray and their thermal properties [41-44, 65-68].

\begin{tabular}{lccc}
\hline Composites & Contents of CNT & Thermal properties & References \\
\hline CNT-Al & $0.5-1.0 \%$ by weight & N/A & {$[44]$} \\
CNT-Cu & $3 \%$ by volume & Higher thermal diffusivity & {$[65]$} \\
CNT-Cu & $5-15 \%$ by volume & Better heat transfer performance & {$[41,66]$} \\
CNT-Cu-SiC & $4-4.5 \%$ by volume & Better heat transfer performance & {$[43,67,68]$} \\
CNT-Cu-AlN & $4-4.5 \%$ by volume & Better heat transfer performance & {$[42,67,68]$} \\
CNT-Cu-BN & $4 \%$ by volume & Better heat transfer performance & {$[67,68]$} \\
\hline
\end{tabular}

In addition to mechanical ball milling, spray drying technology has also been used to disperse CNT within agglomerated metal powders. Spray drying is a process that produces powders from a liquid solution by rapid drying with hot gases. With this method, CNT was mainly embedded on the surface of agglomerated metal powders but hard to be homogenously incorporated inside the individual powder. Figure 11 shows the schematic of the coating fabrication procedure using spray drying MMC powders. As can be seen, a consequence of using spray drying powders is the inhomogeneous distribution of CNT in the cold-sprayed coatings as shown in Figure 12 [44].

As for the properties of cold-sprayed CNT-reinforced MMC coatings, it has been revealed that mechanical properties improved with additional CNT reinforcements. In the CNT-Al MMC coatings, local hardness was found to be higher at CNT-rich zone due to the higher stiffness of CNT [44]. Similar results were also concluded in the CNT-Cu MMC coatings. CNT reinforcements were also found to lead to the improvement of thermal properties in terms of both heat transfer performance and thermal diffusivity $[65,66]$. Table 2 lists the existing CNT-reinforced MMC coatings produced by cold spray and their improved thermal properties [41-44, 65-68]. The existing works clearly demonstrate that cold spray is a promising technology to produce CNT-reinforced MMC coatings.

\section{2D Material-Reinforced MMC Coatings via Cold Spray}

5.1. Graphene-Reinforced MMC Coatings. Graphene, as the single layer of $\mathrm{sp}^{2}$ bonded carbon atoms, has extraordinary mechanical, thermal, and electrical properties, attracting great attentions from both scientific and industrial communities. It is normally applied as reinforcements of MMCs to improve the matrix material properties. The 


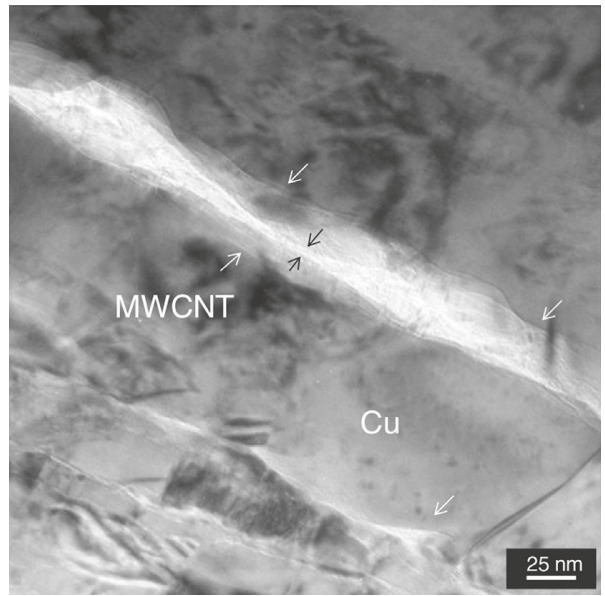

FIGURE 9: TEM imaging of a cold-sprayed CNT-Cu MMC coating produced by low-pressure cold spray [65].
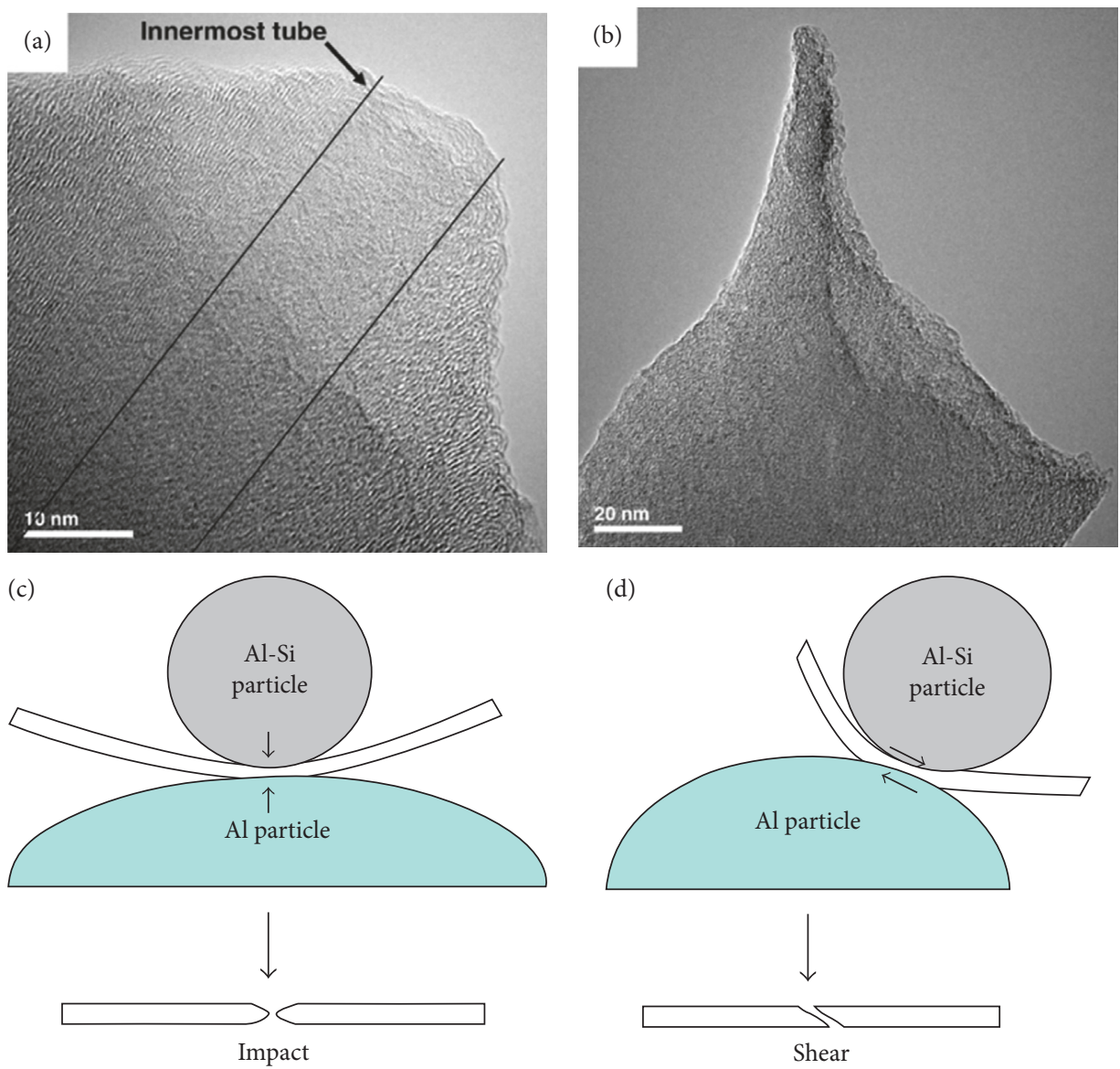

FIGURE 10: TEM imaging of damaged CNT in the cold-sprayed CNT-Cu coatings and their damaging mechanism: (a, c) impact-induced damage and (b, d) shear-induced damage [44].

graphene-reinforced MMCs have exhibited superior properties over the pure metals [69]. Currently, the most common ways for fabricating graphene-reinforced MMCs are a number of powder metallurgy techniques, for example, spark plasma sintering, laser sintering, and hot pressing [70-75]. The existing studies showed great capability of graphene-reinforced
MMCs to improve the material properties, for example, strength [70-72], Young's modulus [72, 76], hardness [72, 76], wear resistance [72-74], and electrical conductivity [75].

Graphene-reinforced MMCs were successfully produced via cold spray in very recent years $[32,33]$. As a key step, preparation of MMC powders is of great importance to the 


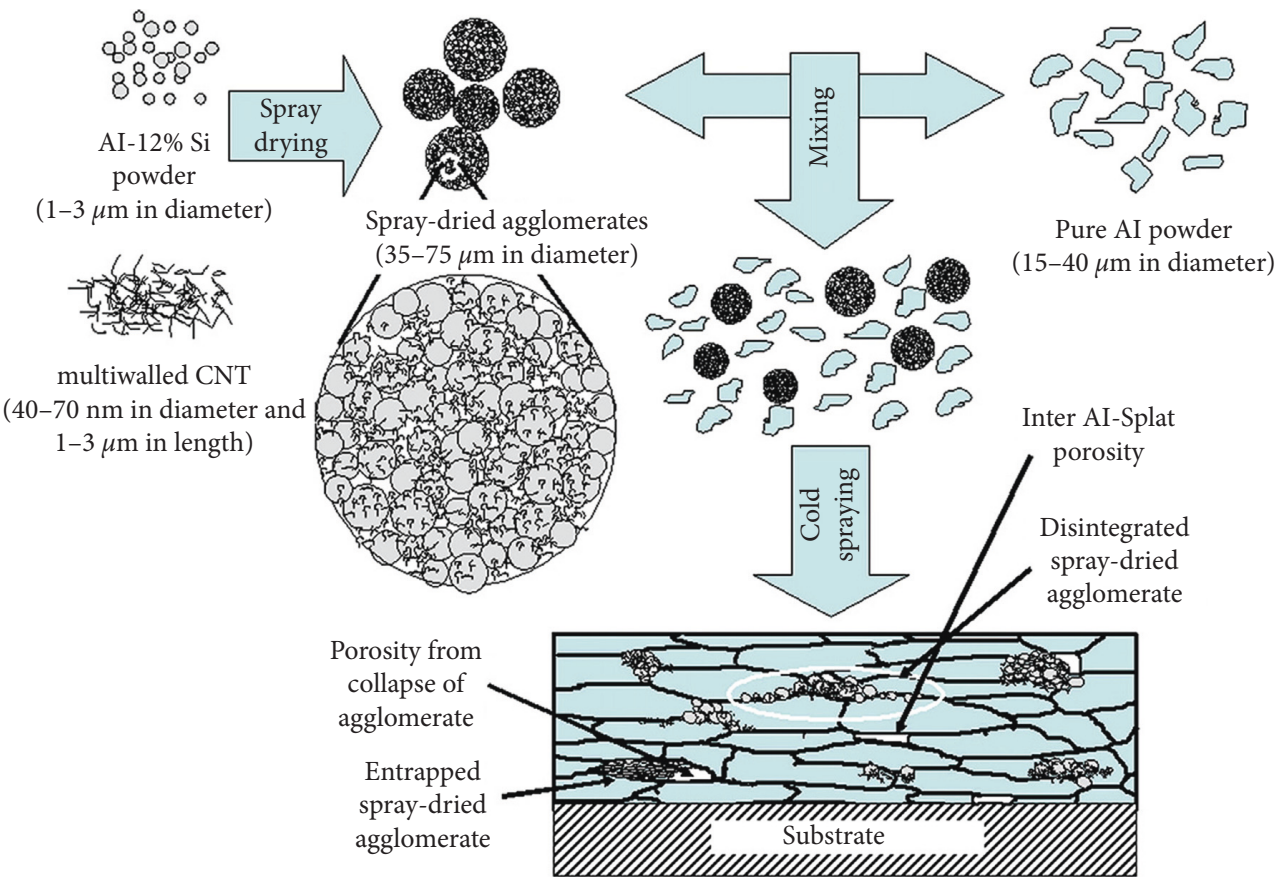

FIGURE 11: Schematic of the coating fabrication procedure using spray drying MMC powders [44].
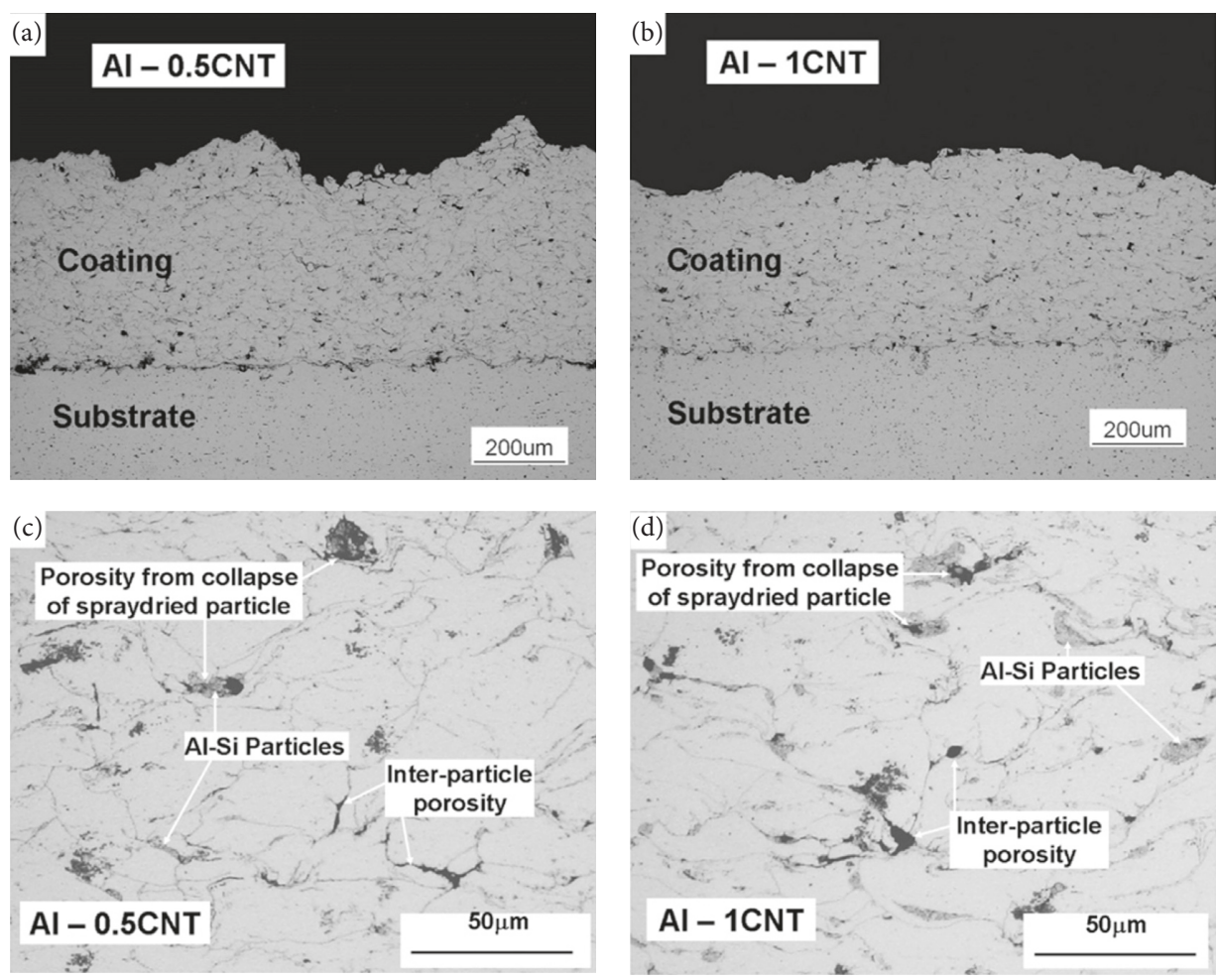

FIGURE 12: SEM imaging of the cross section of cold-sprayed CNT-Al MMC coatings with different CNT contents: (a) CNT content of 0.5\%, (b) CNT content of $1 \%$, and (c, d) high-magnification view [44].

coating deposition process and final coating quality. So far, two manufacturing methods have been used for MMC powder fabrication. In Yin et al.'s work, mechanical ball milling was applied to incorporate graphene nanosheets into spherical $\mathrm{Cu}$ particles [32]. Because the energy for ball milling is not high in that work, graphene nanosheets were mainly embedded on the $\mathrm{Cu}$ particle surface rather than homogenously distributed inside the $\mathrm{Cu}$ particle. Alternatively, in the work of Dardona et al., the graphene-reinforced MMC powders were synthesized through electroless plating 

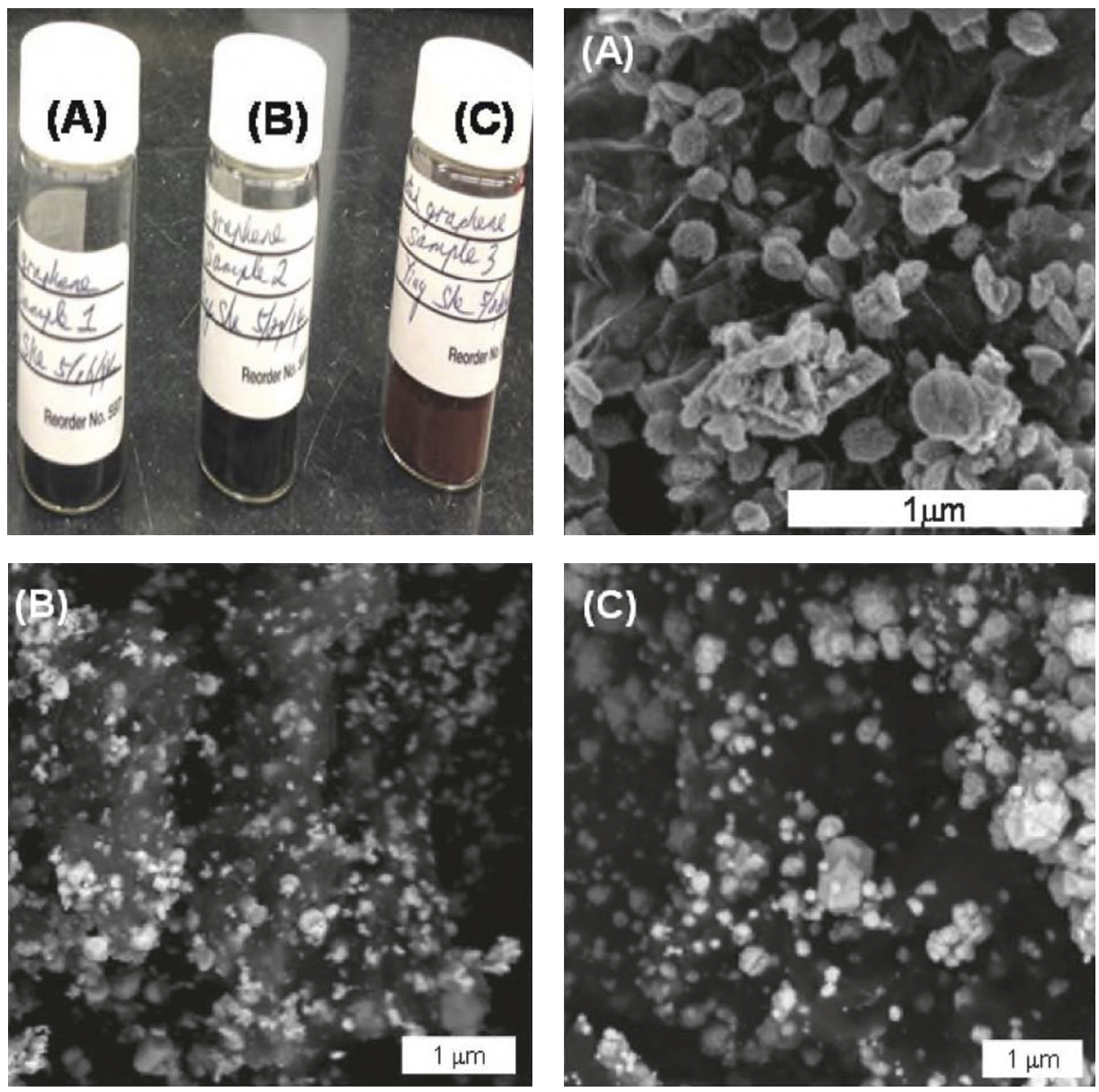

FIGURE 13: Morphology of the graphene-Cu MMC powders produced through electorless plating under different plating time. Digital photo

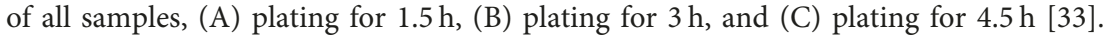

of $\mathrm{Cu}$ film on the surface of graphene nanosheets [33]. Electroless plating is a method that deposits metals onto a solid piece by chemical approach. The piece to be plated is immersed in a reducing agent where metal ions can be changed to metal when catalyzed by certain materials to form a deposit. Figure 13 shows the morphology of the graphene-reinforced $\mathrm{Cu}$ MMC powders produced through electorless plating under different plating time. Powders produced in this way basically have a graphene core and an outside $\mathrm{Cu}$ film. Longer plating time would result in more $\mathrm{Cu}$ phase on the graphene surface as can be seen from Figure 13.

As for the coating microstructure, ball-milled MMC powders resulted in dense and thick coating with uniformly distributed graphene nanosheets as shown Figure 14 . However, the electroless-plated MMC powders seemed to produce a low-quality coating with insufficient cohesion strength and inhomogeneous distribution of graphene nanosheets in the coating, as shown in Figure 15 [32]. This may be due to the low fraction of the $\mathrm{Cu}$ phase in the MMC powders, which significantly limits the effective metallic bonding between interparticles [33]. In terms of the coating properties, currently, only the wear resistance and electrical conductivity have been tested. In Yin et al.'s work, the graphene-reinforced MMC coatings exhibited excellent wear-resistance performance, better than those produced by spark plasma sintering [32]. In the work of Dardona et al., the coating demonstrated worse electrical conductivity than bulk $\mathrm{Cu}$, which was probably due to the low $\mathrm{Cu}$ thickness on the graphene powder surface, poor interparticle bonding, and inhomogeneous distribution of graphene nanosheets in the coating [33].

5.2. $W S_{2}$-Reinforced MMC Coatings. Monolayer tungsten disulfide $\left(\mathrm{WS}_{2}\right)$ has great potential in the optical sector due to its direct band gap and high photoluminescence intensity [34]. It also possesses excellent solid lubrication properties due to the 2D layered structure and easy interlayer sliding. In addition, the special structure of $\mathrm{WS}_{2}$ allows it to be usable in high temperature, high pressure, high vacuum, high load, and with radiation and corrosive media environments $[35,36]$. Moreover, because $\mathrm{WS}_{2}$ has an excellent adsorption capacity on the metal surface, it can be used as reinforcements in MMCs to improve the lubrication performance [77]. The $\mathrm{WS}_{2}-\mathrm{Al}$ MMCs made by sparkling plasma sintering have shown better wear-resistance performance than graphene-Al MMCs under ball-on-disk wear tests, which clearly demonstrates the superiority of $\mathrm{WS}_{2}$ than other lubricants [36]. 

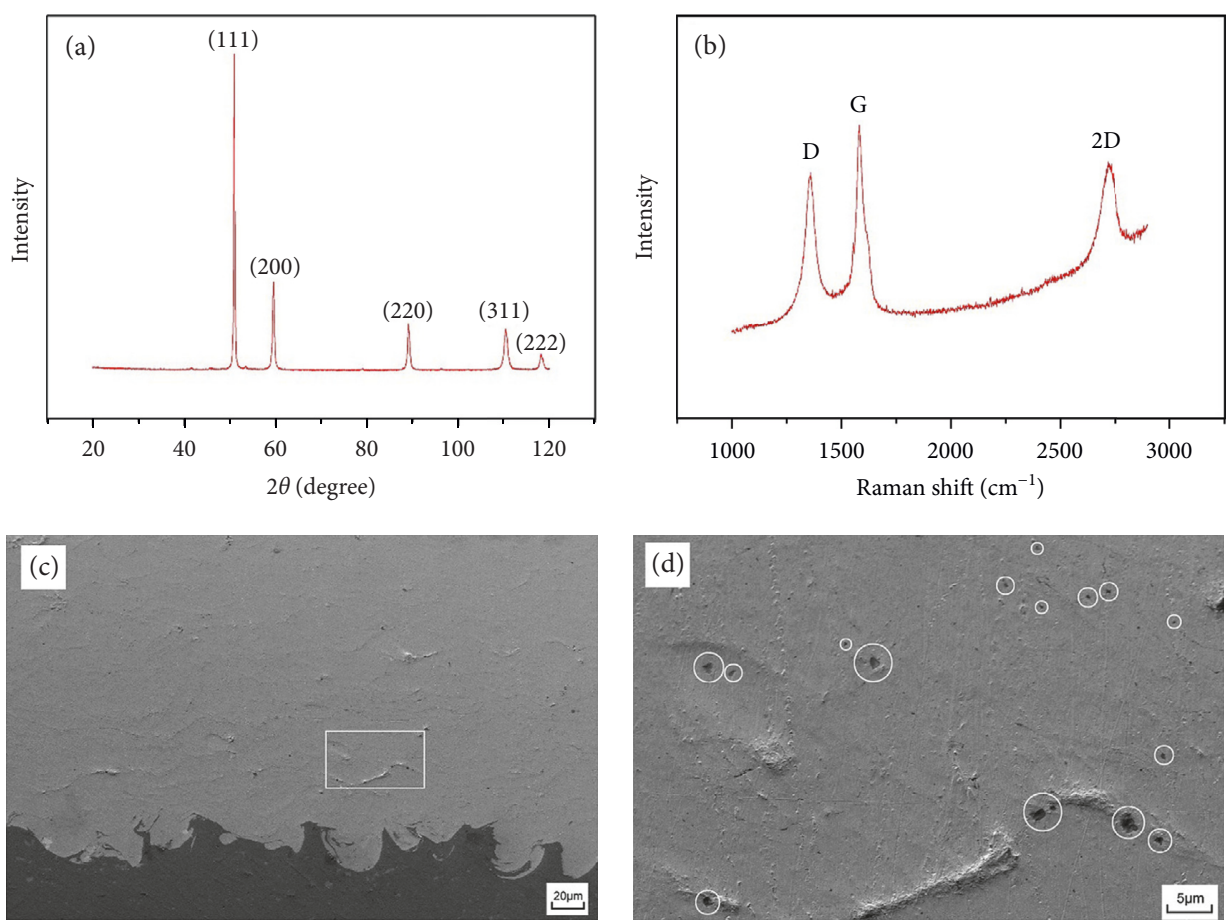

FIGURE 14: Characterization of graphene-Cu MMC coating produced using ball-milled powders: (a) XRD spectrum, (b) Raman spectrum, (c) coating cross-sectional view, and (d) a magnified view [32].
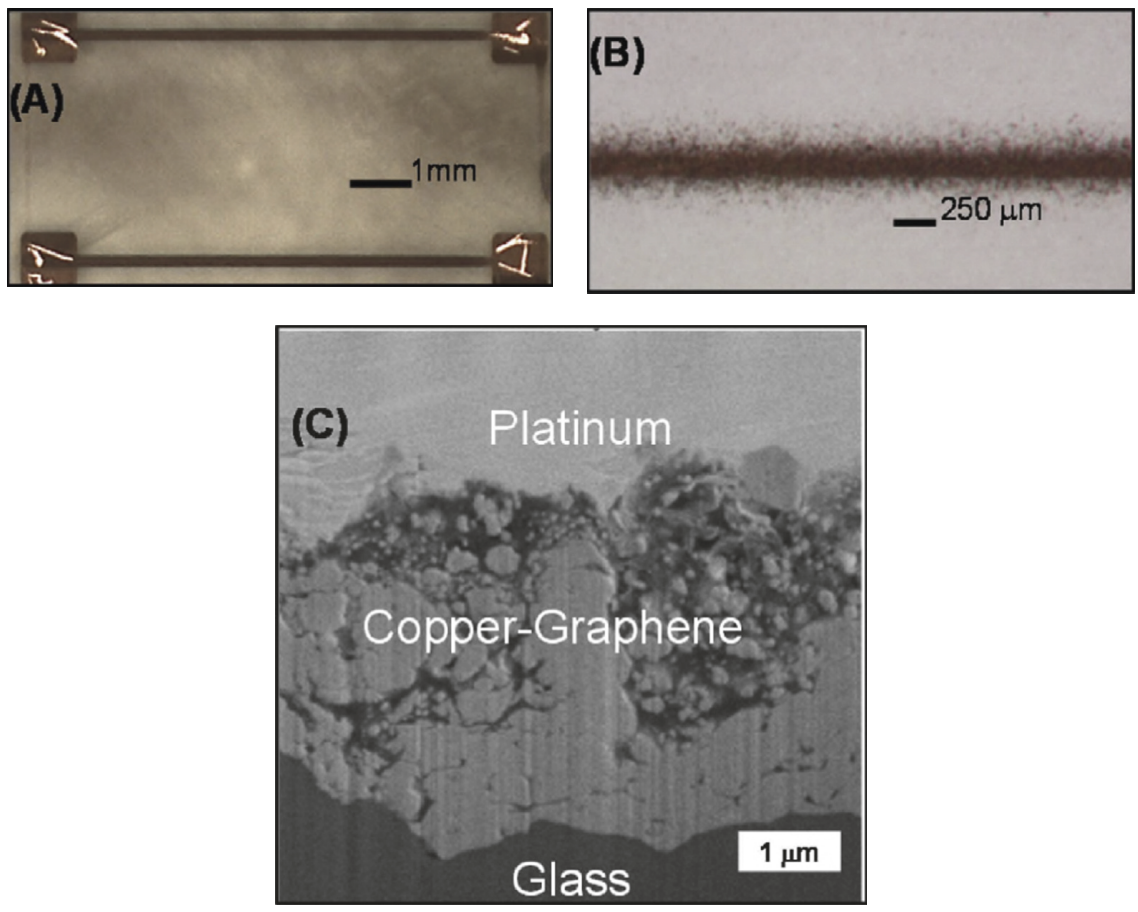

FIGURE 15: Characterization of graphene-Cu MMC coating produced using electroless-plated powders: (A) optical view of two tracks, (B) single-line track, and (C) coating cross-sectional view [33]. 

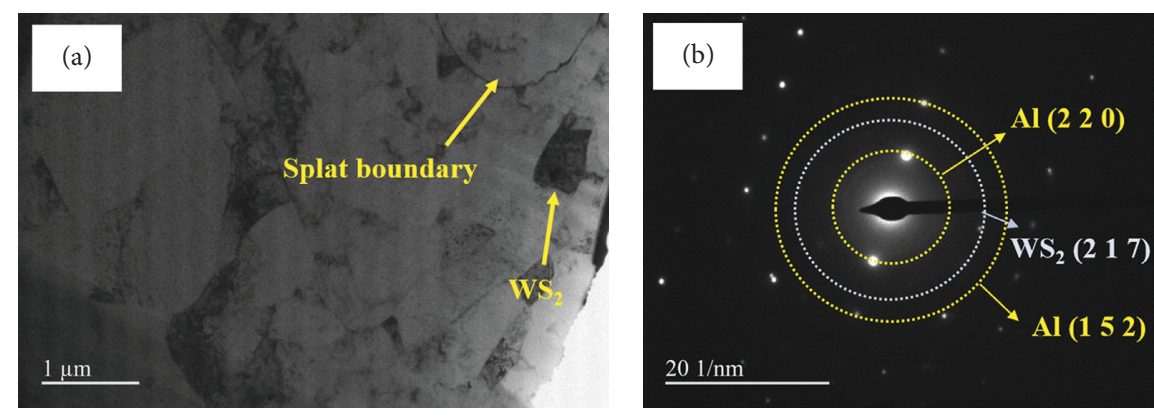

FIGURE 16: TEM imaging of $\mathrm{WS}_{2}$-Al MMC coating: (a) bright field imaging with multiple splats, subgrains, and (b) SAED pattern [78].

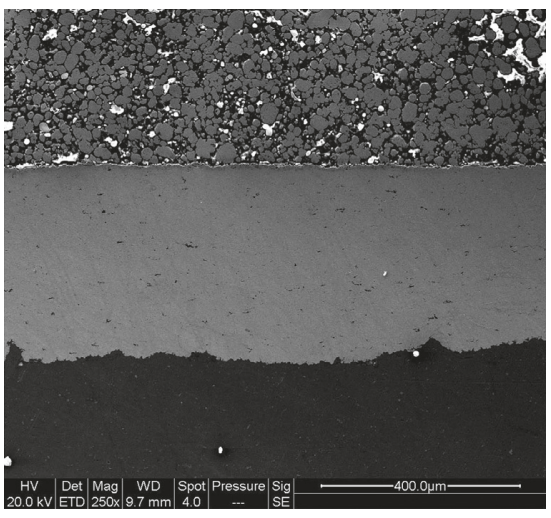

(a)

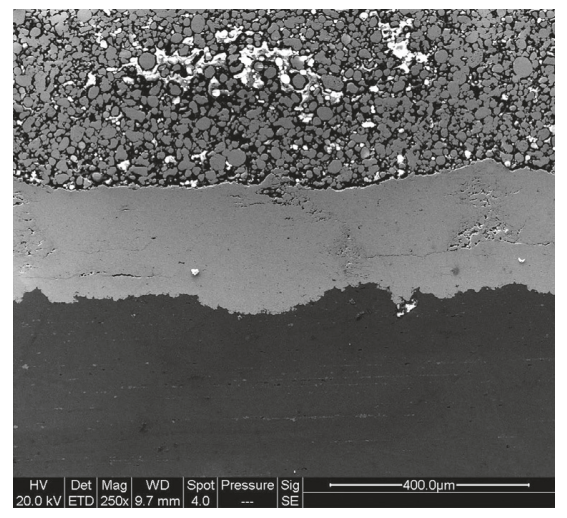

(b)

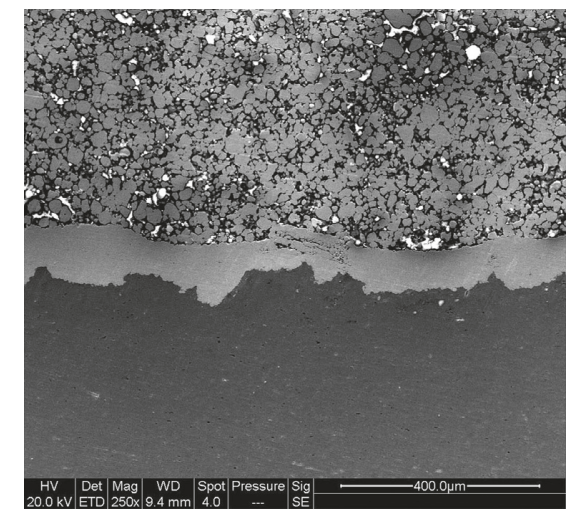

(c)

FIGURE 17: SEM imaging of the cross section of cold-sprayed hBN-Ni MMC coatings produced using (a) unaltered powders, (b) ball-milled powders for $1 \mathrm{~h}$, and (c) ball-milled powders for $2 \mathrm{~h} \mathrm{[39].}$

$\mathrm{WS}_{2}$-Al MMC coatings were produced via cold spray for wear resistance in a recent work [78]. Ball milling technology was used to produce the MMC powders. After low-energy ball milling, Al particles still remained spherical shape, and $\mathrm{WS}_{2}$ was mostly attached on the surface of the $\mathrm{Al}$ particles. The surface morphology of the $\mathrm{WS}_{2}-\mathrm{Al}$ MMC powders is quite similar with the graphene-Cu powders used in Yin et al.'s study [32]. The coatings were then produced using nitrogen under the pressure of $3.8 \mathrm{MPa}$ and temperature of $400^{\circ} \mathrm{C}$. Figure 16 shows the TEM imaging of the coating cross section. As can be seen, $\mathrm{WS}_{2}$ was successfully deposited with $\mathrm{Al}$ onto the carbon steel substrate and uniformly distributed within the coating, which demonstrates the feasibility of cold spray to produce $\mathrm{WS}_{2}$-reinforced MMC coatings. The wear test revealed that the $\mathrm{WS}_{2}$-reinforced MMC coating had an outstanding wear-resistance performance due to the presence of $2 \mathrm{D}$ layered $\mathrm{WS}_{2}$ which aids in shearing of $\mathrm{WS}_{2}$ layers and uniform tribofilm formation comprised of $\mathrm{WS}_{2}$ and $\mathrm{WO}_{3}$.

5.3. hBN-Reinforced MMC Coatings. Hexagonal boron nitride (hBN) nanosheets are 2D crystalline form of hBN, which have a thickness of one to few atomic layers. It is similar in geometry to graphene but having completely different chemical, thermal, and electronic properties. Cold spray has been successfully used for producing hBNreinforced MMC coatings, mainly hBN-Ni coatings [37-40].
Electroless plating was used to encapsulate $\mathrm{hBN}$ powders and to produce hBN-reinforced MMC powders. During the encapsulation process, the MMC particles tended to agglomerate and form large clusters. Therefore, as a comparison, following the electroless plating, ball milling was employed to de-agglomerate the clustered feedstock powders [38]. Both low- and high-energy ball milling methods were employed: low energy can eliminate voids inside the clusters and leads to higher density and uniform particle size; high energy resulted in breakup of agglomerations and destroyed the $\mathrm{Ni}$ encapsulant. Figure 17 shows the SEM imaging of the cross section of cold-sprayed hBN-Ni MMC coatings using various powders. As can be seen, the unaltered hBN-Ni MMC powders resulted in the thickest and densest coatings due to the significant plastic deformation as compared with ball-milled powders which experienced work hardening during the powder preparation process [39]. The tribological study demonstrates that the cold-sprayed hBN-Ni MMC coatings had a very promising wear-resistance performance. They can reduce the friction coefficient by almost $50 \%$ and significantly increase the wear resistance as compared with pure $\mathrm{Ni}$ [40].

\section{3D Nanoparticle-Reinforced MMC Coatings via Cold Spray}

6.1. WC-Reinforced MMC Coatings. Tungsten carbide (WC) has very high hardness and stiffness, which has been widely 

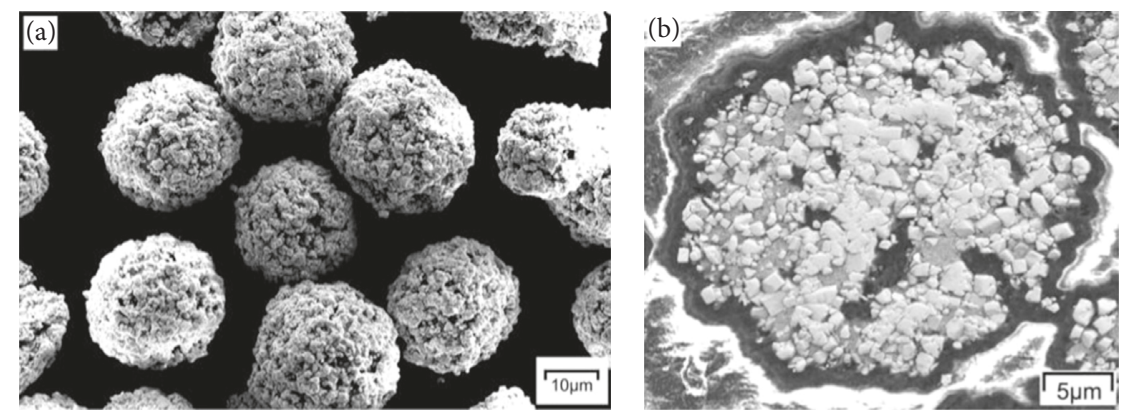

FIGURE 18: Morphology of WC-Co powder: (a) surface morphology and (b) cross-sectional view [84].

TABLE 3: Review of working parameters used for producing cold-sprayed WC-Co coatings [84].

\begin{tabular}{|c|c|c|c|c|c|}
\hline Feedstock & Gas & Pressure $(\mathrm{MPa})$ & Temperature $\left({ }^{\circ} \mathrm{C}\right)$ & Preheating $\left({ }^{\circ} \mathrm{C}\right)$ & Hardness (Hv) \\
\hline \multirow{8}{*}{ WC-12Co } & $\mathrm{He}$ & 3.0 & 600 & 500 & 2053 \\
\hline & $\mathrm{He}$ & 2.0 & 600 & No & $1812 \pm 121$ \\
\hline & $\mathrm{He}$ & 2.0 & 650 & No & $\mathrm{N} / \mathrm{A}$ \\
\hline & $\mathrm{He}$ & 2.0 & 600 & No & $1600-2000$ \\
\hline & $\mathrm{He}$ & 2.0 & 650 & No & 1800 \\
\hline & $\mathrm{N} 2$ & $2.5-3.5$ & 800 & Yes & $1419 \pm 93$ \\
\hline & $\mathrm{N} 2$ & 4.5 & 700 & 250 & 984 \\
\hline & $\mathrm{N} 2$ & 2.4 & $750 \pm 30$ & Yes & $1525 \pm 143$ \\
\hline \multirow{2}{*}{ WC-15Co } & $\mathrm{He}$ & 1.7 & 550 & No & $462 \pm 92$ \\
\hline & $\mathrm{N} 2$ & 4.5 & 800 & 250 & 1480 \\
\hline \multirow{4}{*}{ WC-17Co } & $\mathrm{He}$ & 3.5 & 600 & 200 & 918 \\
\hline & $\mathrm{He}$ & $1.2-1.7$ & 600 & No & $1312 \pm 39,1094 \pm 51$ \\
\hline & N2 & $2.5-3.5$ & 800 & Yes & $1223 \pm 59$ \\
\hline & $\mathrm{N} 2$ & 2.4 & $750 \pm 30$ & Yes & $1316 \pm 80,1625 \pm 115$ \\
\hline WC-25Co & $\mathrm{N} 2$ & 4.0 & 800 & No & $845 \pm 55,981 \pm 58$ \\
\hline WC-10Co & $\mathrm{N} / \mathrm{A}$ & 2.2 & 650 & No & $893 \pm 75$ \\
\hline
\end{tabular}

used in industrial machinery, cutting tools, and abrasives. It is normally present in the form of nanosized powder, sintered or agglomerated in soft Co to generate WC-Co MMCs. WCCo protecting coating is one of the most important products of WC-Co MMCs, commonly used for preventing the underlying base materials from serious wear in aggressive environments [79]. The WC-Co coating fabrication mostly relies on hightemperature thermal spray processes to melt the Co matrix phase in the agglomerated WC-Co powder feedstock for achieving superior cohesion [79-83]. Figure 18 shows the typical morphology of WC-Co powders used for coating fabrications [84]. However, high deposition temperature frequently results in decarburization, phase transformation, and oxidation of hard WC reinforcements or soft Co matrix phase, significantly deteriorating the coating mechanical properties and wear-resistance performance $[80-83,85,86]$. Cold spray can effectively prevent the coating defects in relation to hightemperature processes and thereby has been found to be promising for fabricating WC-Co wear-resistance coatings.

Investigations have revealed that WC-Co particles were difficult to deposit with cold spray due to the lack of the sufficient binder phase to induce the particle plastic deformation. Thereby, the working parameters for fabricating
WC-Co coatings must be extremely high so that WC-Co particles can obtain sufficient kinetic energy to promote the metallic bonding between Co matrix phases during the particle deposition. Table 3 lists the working parameters ever used for producing cold-sprayed WC-Co coatings [87]. As can be seen, cold-sprayed WC-Co coatings were mostly achieved by using compressed high-temperature helium aspropulsive gas or using nitrogen as propulsive gas combined with powder preheating treatment. Although the manufacturing cost is relatively high, cold-sprayed WC-Co coatings have shown several incomparable advantages. It has been proved that cold spray can produce fully dense WC-Co coatings as shown in Figure 19 [87]. The cold-sprayed coatings experienced no decarburization and phase transformation during the fabrication process due to the low working temperature [88-91]. This is a unique advantage that other thermal spray processes cannot achieve. In addition, it is also demonstrated that the Vickers hardness of coldsprayed WC-Co coatings mostly fell into the range between 800 and $2000 \mathrm{Hv}$ as listed in Table 3 [84]. The hardness is much higher than most metals, and comparable to or even higher than thermal-sprayed coatings. In terms of tribological performance, cold-sprayed WC-Co coatings showed lower wear 

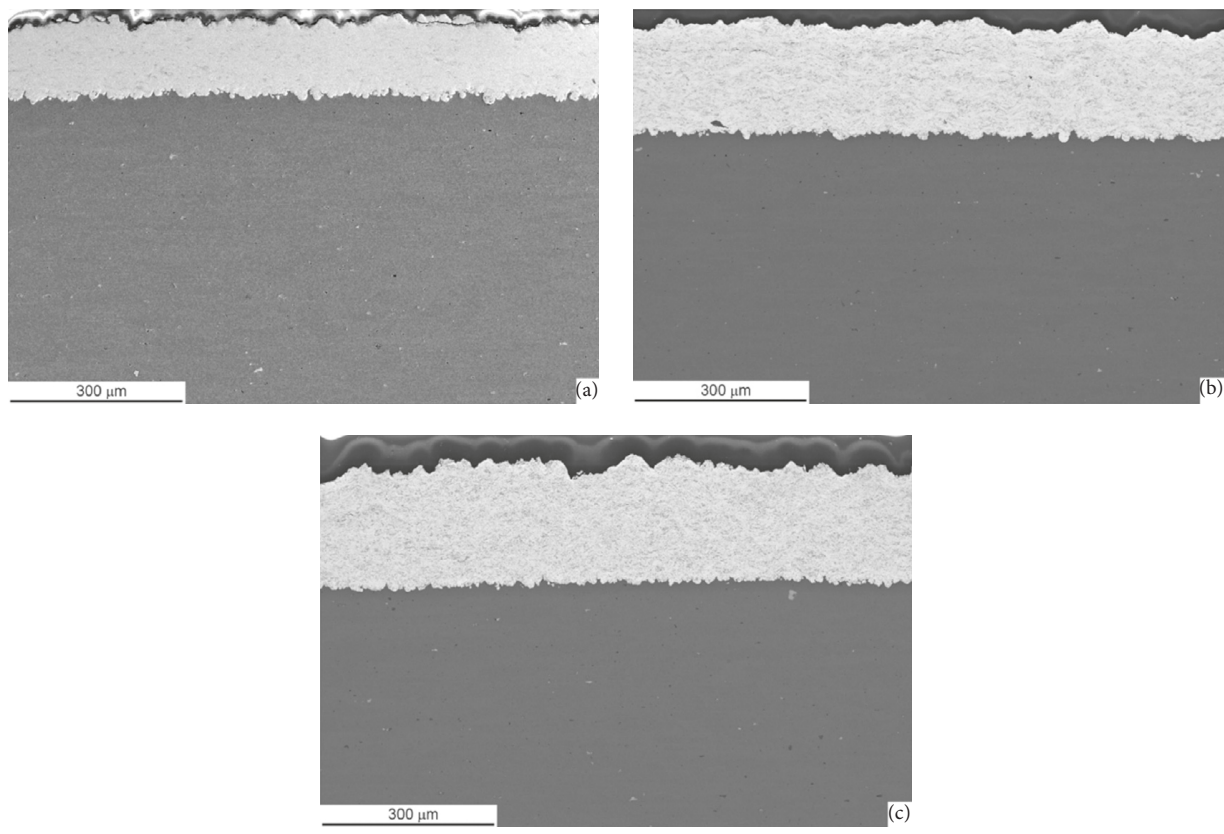

FIGURE 19: SEM imaging of the cross section of WC-Co coatings: (a)WC-12Co, (b)WC-17Co, and (c)WC-25Co coatings deposited onto the $\mathrm{Al}$ 7075-T6 substrate [87].
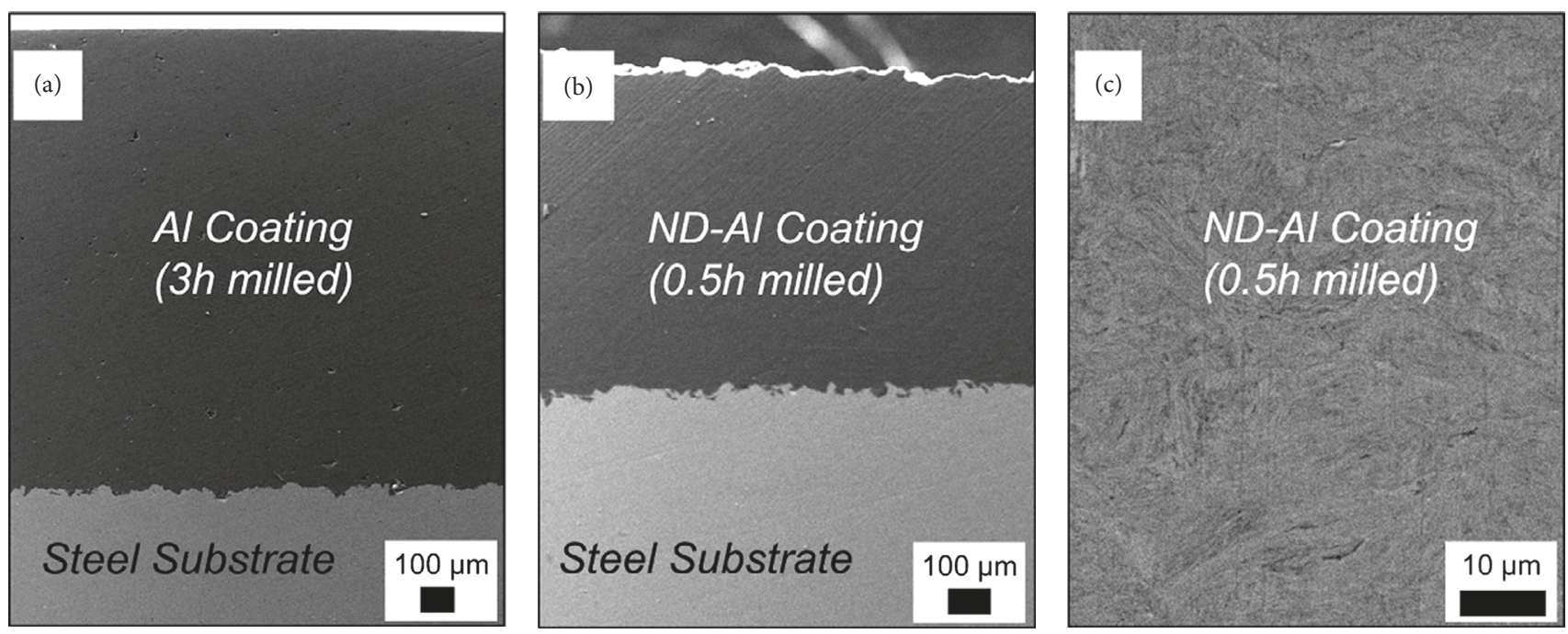

FIGURE 20: SEM imaging of the cross section of cold-sprayed nanodiamond-Al MMC coatings: (a) pure Al coating, (b) nanodiamond-Al MMC coating, and (c) magnified view.

rate than high-velocity oxy-fuel-sprayed coatings under both ball-on-disk sliding and dry abrasion tests, exhibiting superior wear-resistance performance [90, 92-94].

6.2. Diamond-Reinforced MMC Coatings. Diamond is known to possess extremely high hardness, allowing it to be used as an excellent wear-resistance material. However, for the same reason, it is difficult to be machined, which in turn limits its direct applications. Diamond-reinforced MMCs are novel materials in which the metallic phase acts as a binder, while the diamond phase helps to improve the material properties. Currently, the common ways to fabricate bulk diamond-reinforced MMCs or MMC coatings are powder metallurgy [95-99], pressure infiltration techniques [100-104], and thermal spray techniques [105-109]. These methods mostly require extremely high processing temperatures to melt the metal binder, thereby significantly increasing the risk of the metal phase transformation and diamond graphitization [97]. Cold spray would greatly avoid the risk of high-temperature-induced diamond phase graphitization and simultaneously retain high diamond contents [110, 111]. 

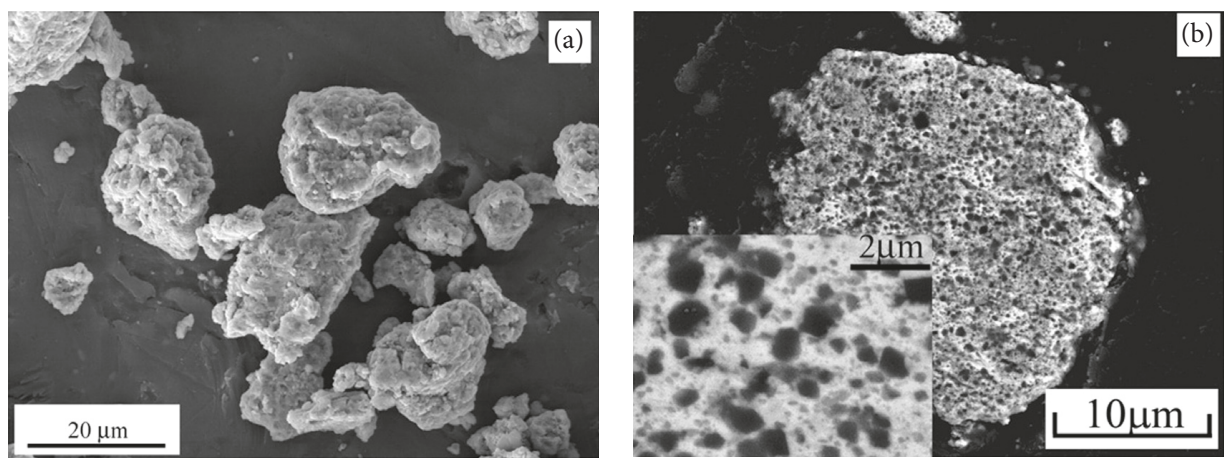

Figure 21: SEM imaging of the cBN-NiCrAl MMC powder after ball milling for $40 \mathrm{~h}$ : (a) morphology and (b) cross section. The bright regions and dark dots in (b) correspond to $\mathrm{NiCrAl}$ alloy and $\mathrm{cBN}$ particles.
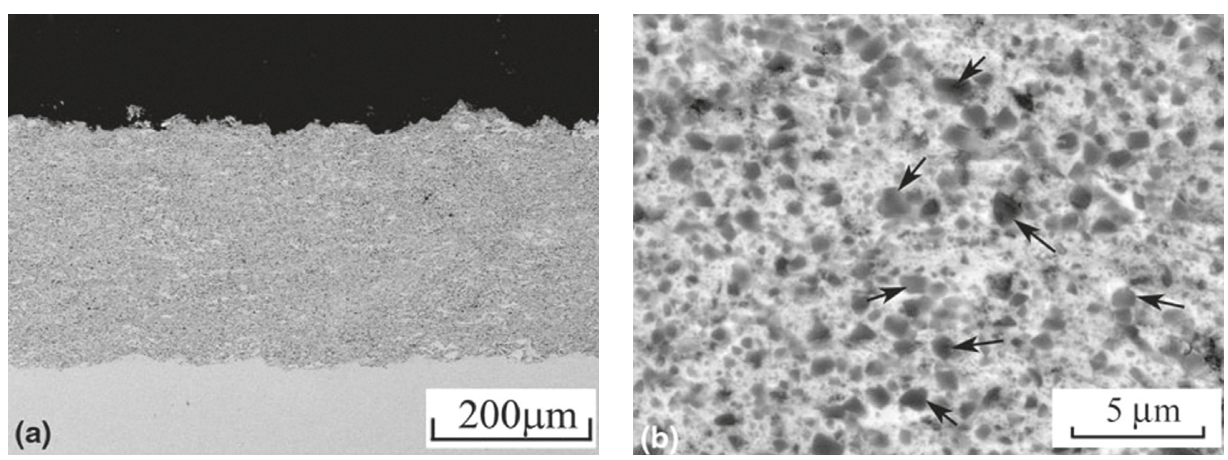

Figure 22: SEM imaging of cold sprayed cBN-NiCrAl MMC coatings with 40 vol.\% cBN [49]. The bright regions and dark dots in (b) correspond to NiCrAl alloy and $\mathrm{cBN}$ particles.

Nanodiamond-reinforced MMC coatings have been successfully fabricated via cold spray $[45,46]$. Analogous to most MMC powders, ball milling technology was used to produce the nanodiamond-reinforced MMC powders. In order to maximize the performance of the MMC powders, the effect of ball milling parameters and nanodiamond content on the powder properties were studied. The results revealed that powder properties including particle size distribution, hardness, and uniformity of reinforcements can be well controlled through modifying the nanodiamond content, milling time, and BPR ratio [45]. Figure 20 shows the SEM imaging of cold-sprayed nanodiamond-Al MMC coatings. The MMC coatings exhibited thick and dense features with homogenously dispersed nanodiamond reinforcements. In addition, coatings showed significant strengthening as compared with the pure Al coating. The reason for the mechanical performance strengthening was attributed to the dispersion strengthening, grain refinement, and strain hardening [46]. So far, property testing on the nanodiamond-reinforced MMC coatings was still very limited. As diamond also possesses high hardness and thermal and electrical conductivity, such coating may also possess high wear-resistance performance and thermal performance. Therefore, further investigations are encouraged in the future work.
6.3. cBN-Reinforced MMC Coatings. Cubic boron nitride $(\mathrm{cBN})$, having similar crystal structure with diamond, is the second-known hardest material after diamond. It is synthesized from hBN under conditions similar to those used to produce synthetic diamond from graphite. It has been increasingly used as cutting and drilling tools in substitution for diamond-based tools owing to its superior thermal stability and chemical inertness. It is suitable especially for processing hard ferrous materials to which diamond is not applicable since diamond reacts with these materials at high temperature [112].

Cold spray has been used to fabricate $\mathrm{CBN}-\mathrm{NiCrAl} \mathrm{MMC}$ coatings [47-50]. As the most prevailing technology for MMC powder production, ball milling was also used to produce the $c B N$-reinforced MMC powders. Figure 21 shows the SEM imaging of the $\mathrm{CBN}-\mathrm{NiCrAl} \mathrm{MMC}$ powders after ball milling for $40 \mathrm{~h}$. As can be seen, the MMC powders exhibited a near spherical shape; the $\mathrm{cBN}$ particles were uniformly distributed in the $\mathrm{NiCrAl}$ alloy matrix [47]. Figure 22 shows a SEM imaging of cold-sprayed cBN$\mathrm{NiCrAl}$ MMC coatings with 40 vol.\% of cBN particles [49]. Experimental results clearly showed that the as-sprayed coating had a rather dense microstructure with uniformly dispersed nano-cBN particles. In addition, no phase transformation and grain growth of the NiCrAl matrix 
occurred during the spraying process. The hardness of the 20 vol.\% and 40 vol.\% cBN-NiCrAl coatings were 1063 and $1175 \mathrm{Hv}$, respectively [47-49].

In addition, annealing treatment was found to significantly affect the microstructure of the cBN-reinforced $\mathrm{NiCrAl} \mathrm{MMC} \mathrm{coatings.} \mathrm{The} \mathrm{nanostructure} \mathrm{in} \mathrm{the} \mathrm{MMC}$ coatings could be retained when the annealing temperature was below $825^{\circ} \mathrm{C}$. However, a significant growth of dispersion reinforcements due to the occurrence of reaction between $\mathrm{cBN}$ particles and the $\mathrm{NiCrAl}$ matrix was observed at an annealing temperature higher than $825^{\circ} \mathrm{C}$. This phenomenon led to a reduction of hardness as the annealing temperature increased. Furthermore, the tribological performance of the cold sprayed cBN-NiCrAl MMC coatings was also investigated. The as-sprayed coatings exhibited excellent wear-resistance performance. Coatings with 20 vol.\% nano-cBN resulted in a wear resistance which is comparable to the HVOF-sprayed WC-12Co. Low-temperature heat treatment $\left(750^{\circ} \mathrm{C}\right.$ for $\left.5 \mathrm{~h}\right)$ would further improve the wearresistance performance due to the promoted interparticle bonding strength [48].

\section{Summary and Perspectives}

Cold spray is a solid-state coating deposition technology which can retain the original properties of feedstock in the final coating and prevent the adverse influence caused by high working temperature. As a low-temperature process, cold spray has been showing great potential in producing high-performance metal coatings with nanostructure. This paper provides an overview of cold-sprayed metal coatings with nanostructure. Basically, cold-sprayed coatings with nanostructure can be produced in the following three ways. Firstly, nanocrystallization in the form of grain refinement always occurs at the interparticle and coating-substrate interfacial regions during the deposition process due to the dynamic recrystallization, which can result in nanostructured grains within the cold-sprayed coating. This theory has been well understood so far. Secondly, the starting feedstock for cold spray is nanocrystalline powders; then the coating can retain the nanostructure of the starting powders. In this aspect, cold-sprayed nanocrystalline coatings are very promising as cold spray can completely retain the nanostructure of the starting powders in the coating. In the future, the relevant work should be continued, and special attention can be paid on the coating densification and coating property exploration. Thirdly, cold-sprayed nanomaterial-reinforced MMC coatings also exhibit nanostructure. In this field, although ball milling has been accepted as the most commonly used method for producing nanomaterial-reinforced MMC powders, the effect of milling parameters on the powder property is still now well clarified. Also, new technologies for producing more uniform MMC powders are needed. Therefore, preparation of nanomaterial-reinforced MMC powders will be a research focus in the future work. Moreover, investigation on the properties of cold-sprayed nanomaterial-reinforced MMC coatings will be another highlight as currently such property tests are still very limited.

\section{Conflicts of Interest}

The authors declare that they have no conflicts of interest.

\section{References}

[1] A. Papyrin, "Cold spray technology," Advanced Materials and Processing, vol. 159, pp. 49-51, 2001.

[2] P. C. King, S. H. Zahiri, and M. Jahedi, "Focused ion beam micro-dissection of cold-sprayed particles," Acta Materialia, vol. 56, no. 19, pp. 5617-5626, 2008.

[3] N. M. Melendez, V. V. Narulkar, G. A. Fisher, and A. G. McDonald, "Effect of reinforcing particles on the wear rate of low-pressure cold-sprayed WC-based MMC coatings," Wear, vol. 306, no. 1-2, pp. 185-195, 2013.

[4] S. Dosta, M. Couto, and J. M. Guilemany, "Cold spray deposition of a WC-25Co cermet onto Al7075-T6 and carbon steel substrates," Acta Materialia, vol. 61, no. 2, pp. 643-652, 2013.

[5] M. Grujicic, C. L. C. Zhao, W. S. W. DeRosset, and D. Helfritch, "Adiabatic shear instability based mechanism for particles/substrate bonding in the cold-gas dynamicspray process," Materials and Design, vol. 25, no. 8, pp. 681-688, 2004.

[6] H. J. Choi, M. Lee, and J. Y. Lee, "Application of a cold spray technique to the fabrication of a copper canister for the geological disposal of CANDU spent fuels," Nuclear Engineering and Design, vol. 240, no. 10, pp. 2714-2720, 2010.

[7] V. K. Champagne, "The repair of magnesium rotorcraft components by cold spray," Journal of Failure Analysis and Prevention, vol. 8, no. 2, pp. 164-175, 2008.

[8] S. Yin, X. Wang, X. Suo et al., "Deposition behavior of thermally softened copper particles in cold spraying," Acta Materialia, vol. 61, no. 14, pp. 5105-5118, 2013.

[9] T. Klassen, H. Assadi, H. Kreye, and F. Gartner, "Cold spraying-a materials perspective," Acta Materialia, vol. 116, pp. 382-407, 2016.

[10] M. R. Rokni, S. R. Nutt, C. A. Widener, V. K. Champagne, and R. H. Hrabe, "Review of relationship between particle deformation, coating microstructure, and properties in highpressure cold spray," Journal of Thermal Spray Technology, vol. 26, no. 6, pp. 1-48, 2017.

[11] S. Yin, M. Meyer, W. Li et al., "Gas flow, particle acceleration, and heat transfer in cold spray: a review in cold spray: a review," Journal of Thermal Spray Technology, vol. 25, no. 5, pp. 1-23, 2016.

[12] S. Yin, X. F. Wang, W. Y. Li, and H. E. Jie, "Effect of substrate hardness on the deformation behavior of subsequently incident particles in cold spraying," Applied Surface Science, vol. 257, no. 17, pp. 7560-7565, 2011.

[13] T. C. Jen, L. Li, W. Cui, Q. Chen, and X. Zhang, "Numerical investigations on cold gas dynamic spray process with nanoand microsize particles," International Journal of Heat and Mass Transfer, vol. 48, no. 21-22, pp. 4384-4396, 2005.

[14] J. Liu, H. Cui, X. Zhou, X. Wu, and J. Zhang, "Nanocrystalline copper coatings produced by cold spraying," Metals and Materials International, vol. 18, no. 1, pp. 121128, 2012.

[15] K. Kim, M. Watanabe, J. Kawakita, and S. Kuroda, "Grain refinement in a single titanium powder particle impacted at high velocity," Scripta Materialia, vol. 59, no. 7, pp. 768-771, 2008 . 
[16] C. Lee and J. Kim, "Microstructure of kinetic spray coatings: a review," Journal of Thermal Spray Technology, vol. 24, no. 4, pp. 592-610, 2015.

[17] P. C. King, S. H. Zahiri, and M. Jahedi, "Microstructural refinement within a cold-sprayed copper particle," Metallurgical and Materials Transactions A, vol. 40, no. 9, pp. 2115-2123, 2009.

[18] M. R. Rokni, C. A. Widener, and V. R. Champagne, "Microstructural evolution of 6061 aluminum gas-atomized powder and high-pressure cold-sprayed deposition," Journal of Thermal Spray Technology, vol. 23, no. 3, pp. 514-524, 2014.

[19] X.-T. Luo, C.-X. Li, F.-L. Shang, G.-J. Yang, Y.-Y. Wang, and C.-J. Li, "High velocity impact induced microstructure evolution during deposition of cold spray coatings: a review," Surface and Coatings Technology, vol. 254, pp. 11-20, 2014.

[20] Y. Zou, W. Qin, E. Irissou, J. G. Legoux, S. Yue, and J. A. Szpunar, "Dynamic recrystallization in the particle/particle interfacial region of cold-sprayed nickel coating: electron backscatter diffraction characterization," Scripta Materialia, vol. 61, no. 9, pp. 899-902, 2009.

[21] Y. Zou, D. Goldbaum, J. A. Szpunar, and S. Yue, "Microstructure and nanohardness of cold-sprayed coatings: electron backscattered diffraction and nanoindentation studies," Scripta Materialia, vol. 62, no. 6, pp. 395-398, 2010.

[22] L. Ajdelsztajn, B. Jodoin, G. E. Kim, and J. M. Schoenung, "Cold spray deposition of nanocrystalline aluminum alloys," Metallurgical and Materials Transactions A, vol. 36, no. 3, pp. 657-666, 2005.

[23] L. Ajdelsztajn, A. Zúñiga, B. Jodoin, and E. J. Lavernia, "Cold-spray processing of a nanocrystalline $\mathrm{Al}-\mathrm{Cu}-\mathrm{Mg}-\mathrm{Fe}-$ Ni alloy with Sc," Journal of Thermal Spray Technology, vol. 15, no. 2, pp. 184-190, 2006.

[24] L. Ajdelsztajn, B. Jodoin, and J. M. Schoenung, "Synthesis and mechanical properties of nanocrystalline $\mathrm{Ni}$ coatings produced by cold gas dynamic spraying," Surface and Coatings Technology, vol. 201, no. 3-4, pp. 1166-1172, 2006.

[25] P. Richer, B. Jodoin, L. Ajdelsztajn, and E. J. Lavernia, "Substrate roughness and thickness effects on cold spray nanocrystalline Al-Mg coatings," Journal of Thermal Spray Technology, vol. 15, no. 2, pp. 246-254, 2006.

[26] P. Sudharshan Phani, V. Vishnukanthan, and G. Sundararajan, "Effect of heat treatment on properties of cold sprayed nanocrystalline copper alumina coatings," Acta Materialia, vol. 55, no. 14, pp. 4741-4751, 2007.

[27] Y. Y. Zhang, X. K. Wu, H. Cui, and J. S. Zhang, "Cold-spray processing of a high density nanocrystalline aluminum alloy 2009 coating using a mixture of as-atomized and ascryomilled powders," Journal of Thermal Spray Technology, vol. 20, no. 5, pp. 1125-1132, 2011.

[28] S. Tria, O. Elkedim, R. Hamzaoui et al., "Deposition and characterization of cold sprayed nanocrystalline NiTi," Powder Technology, vol. 210, no. 2, pp. 181-188, 2011.

[29] J. Liu, X. Zhou, X. Zheng, H. Cui, and J. Zhang, "Tribological behavior of cold-sprayed nanocrystalline and conventional copper coatings," Applied Surface Science, vol. 258, no. 19, pp. 7490-7496, 2012.

[30] R. Ghelichi, S. Bagherifard, D. Mac Donald et al., "Fatigue strength of $\mathrm{Al}$ alloy cold sprayed with nanocrystalline powders," International Journal of Fatigue, vol. 65, pp. 51-57, 2014.

[31] M. Kumar, H. Singh, N. Singh et al., "Development of nanocrystalline cold sprayed Ni-20Cr coatings for high temperature oxidation resistance," Surface and Coatings Technology, vol. 266, pp. 122-133, 2015.
[32] S. Yin, Z. Zhang, E. J. Ekoi et al., "Novel cold spray for fabricating graphene-reinforced metal matrix composites," Materials Letters, vol. 196, pp. 172-175, 2017.

[33] S. Dardona, J. Hoey, Y. She, and W. R. Schmidt, "Direct write of copper-graphene composite using micro-cold spray," AIP Advances, vol. 6, no. 8, p. 085013, 2016.

[34] K. M. McCreary, A. T. Hanbicki, G. G. Jernigan, J. C. Culbertson, and B. T. Jonker, "Synthesis of large-area WS2 monolayers with exceptional photoluminescence," Scientific Reports, vol. 6, no. 1, p. 19159, 2016.

[35] X. Zhang, H. Xu, J. Wang et al., "Synthesis of ultrathin WS2 nanosheets and their tribological properties as lubricant additives," Nanoscale Research Letters, vol. 11, no. 1, p. 442, 2016.

[36] S. Rengifo, A Comparison between Graphene and WS2 as Solid Lubricant Additives to Aluminum for Automobile Applications, M.S. thesis, Florida International University, Miami, FL, USA, 2015.

[37] I. Smid, A. E. Segall, P. Walia, G. Aggarwal, T. J. Eden, and J. K. Potter, "Cold-sprayed Ni-hBN self-lubricating coatings," Tribology Transactions, vol. 55, no. 5, pp. 599-605, 2012.

[38] M. Neshastehriz, I. Smid, and A. E. Segall, "In-situ agglomeration and de-agglomeration by milling of nanoengineered lubricant particulate composites for cold spray deposition," Journal of Thermal Spray Technology, vol. 23, no. 7, pp. 1191-1198, 2014.

[39] M. Neshastehriz, Influence of Pre-Process Work Hardening of Nickel Encapsulated Hexagonal Boron Nitride Powders on Cold Spray Coatings, The Pennsylvania State University, State College, PA, USA, 2014.

[40] L. M. Stark, Engineered Self-Lubricating Coatings Utilizing Cold Spray Technology, The Pennsylvania State University, State College, PA, USA, 2010.

[41] E. J. T. Pialago and C. W. Park, "Cold spray deposition characteristics of mechanically alloyed Cu-CNT composite powders," Applied Surface Science, vol. 308, pp. 63-74, 2014.

[42] E. J. T. Pialago, O. K. Kwon, M. S. Kim, and C. W. Park, "Ternary Cu-CNT-AlN composite coatings consolidated by cold spray deposition of mechanically alloyed powders," Journal of Alloys and Compounds, vol. 650, pp. 199-209, 2015.

[43] E. J. T. Pialago, O. K. Kwon, and C. W. Park, "Cold spray deposition of mechanically alloyed ternary $\mathrm{Cu}-\mathrm{CNT}-\mathrm{SiC}$ composite powders," Ceramics International, vol. 41, no. 5, pp. 6764-6775, 2015.

[44] S. R. Bakshi, V. Singh, K. Balani, D. G. McCartney, S. Seal, and A. Agarwal, "Carbon nanotube reinforced aluminum composite coating via cold spraying," Surface and Coatings Technology, vol. 202, no. 21, pp. 5162-5169, 2008.

[45] D. J. Woo, B. Sneed, F. Peerally et al., "Synthesis of nanodiamond-reinforced aluminum metal composite powders and coatings using high-energy ball milling and cold spray," Carbon, vol. 63, pp. 404-415, 2013.

[46] D. J. Woo, F. C. Heer, L. N. Brewer, J. P. Hooper, and S. Osswald, "Synthesis of nanodiamond-reinforced aluminum metal matrix composites using cold-spray deposition," Carbon, vol. 86, pp. 15-25, 2015.

[47] X. T. Luo, G. J. Yang, and C. J. Li, "Multiple strengthening mechanisms of cold-sprayed $\mathrm{cBNp} / \mathrm{NiCrAl}$ composite coating," Surface and Coatings Technology, vol. 205, no. 20, pp. 4808-4813, 2011.

[48] X. T. Luo, E. J. Yang, F. L. Shang, G. J. Yang, C. X. Li, and C. J. Li, "Microstructure, mechanical properties, and two-body 
abrasive wear behavior of cold-sprayed 2 vol.\% cubic BNNiCrAl nanocomposite coating," Journal of Thermal Spray Technology, vol. 23, no. 7, pp. 1181-1190, 2014.

[49] X. T. Luo and C. J. Li, "Thermal stability of microstructure and hardness of cold-sprayed cBN/NiCrAl nanocomposite coating," Journal of Thermal Spray Technology, vol. 21, no. 3-4, pp. 578-585, 2012.

[50] X. T. Luo, G. J. Yang, C. J. Li, and K. Kondoh, "High strain rate induced localized amorphization in cubic BN/NiCrAl nanocomposite through high velocity impact," Scripta Materialia, vol. 65, no. 7, pp. 581-584, 2011.

[51] H. Assadi, F. Gärtner, T. Stoltenhoff, and H. Kreye, "Bonding mechanism in cold gas spraying," Acta Materialia, vol. 51, no. 15, pp. 4379-4394, 2003.

[52] M. R. Rokni, C. A. Widener, and G. A. Crawford, "Microstructural evolution of $7075 \mathrm{Al}$ gas atomized powder and high-pressure cold sprayed deposition," Surface and Coatings Technology, vol. 251, pp. 254-263, 2014.

[53] K. Kim, M. Watanabe, and S. Kuroda, "Thermal softening effect on the deposition efficiency and microstructure of warm sprayed metallic powder," Scripta Materialia, vol. 60, no. 8, pp. 710-713, 2009.

[54] K. Kang, H. Park, G. Bae, and C. Lee, "Microstructure and texture of $\mathrm{Al}$ coating during kinetic spraying and heat treatment," Journal of Materials Science, vol. 47, no. 9, pp. 4053-4061, 2012.

[55] Q. Wang, N. Birbilis, and M. X. Zhang, "Interfacial structure between particles in an aluminum deposit produced by cold spray," Materials Letters, vol. 65, no. 11, pp. 1576-1578, 2011.

[56] M. A. Meyers, A. Mishra, and D. J. Benson, "Mechanical properties of nanocrystalline materials," Progress in Materials Science, vol. 51, no. 4, pp. 427-556, 2006.

[57] A. I. Gusev and A. A. Rempel, Nanocrystalline Materials, Cambridge International Science Publishing, Great Abington, Cambridge, UK, 2004.

[58] X. Wang, Q. Li, J. Xie et al., "Fabrication of ultralong and electrically uniform single-walled carbon nanotubes on clean substrates," Nano Letters, vol. 9, no. 9, pp. 3137-3141, 2009.

[59] J. L. Song, W. G. Chen, L. L. Dong, J. J. Wang, and N. Deng, "An electroless plating and planetary ball milling process for mechanical properties enhancement of bulk $\mathrm{CNTs} / \mathrm{Cu}$ composites," Journal of Alloys and Compounds, vol. 720, pp. 54-62, 2017.

[60] B. Cheng, R. Bao, J. Yi et al., "Interface optimization of $\mathrm{CNT} / \mathrm{Cu}$ composite by forming $\mathrm{TiC}$ nanoprecipitation and low interface energy structure via spark plasma sintering," Journal of Alloys and Compounds, vol. 722, pp. 852-858, 2017.

[61] D. Kaewsai, A. Watcharapasorn, P. Singjai, S. Wirojanupatump, P. Niranatlumpong, and S. Jiansirisomboon, "Thermal sprayed stainless steel/carbon nanotube composite coatings," Surface and Coatings Technology, vol. 205, no. 7, pp. 2104-2112, 2010.

[62] S. Moonngam, P. Tunjina, D. Deesom, and C. Banjongprasert, "Fe-Cr/CNTs nanocomposite feedstock powders produced by chemical vapor deposition for thermal spray coatings," Surface and Coatings Technology, vol. 306, pp. 323-327, 2016.

[63] W. A. Curtin and B. W. Sheldon, "CNT-reinforced ceramics and metals," Materials Today, vol. 7, no. 11, pp. 44-49, 2004.

[64] A. Dorri Moghadam, E. Omrani, P. L. Menezes, and P. K. Rohatgi, "Mechanical and tribological properties of self-lubricating metal matrix nanocomposites reinforced by carbon nanotubes (CNTs) and graphene-a review," Composites Part B: Engineering, vol. 77, pp. 402-420, 2015.
[65] S. Cho, K. Takagi, H. Kwon et al., "Multi-walled carbon nanotube-reinforced copper nanocomposite coating fabricated by low-pressure cold spray process," Surface and Coatings Technology, vol. 206, no. 16, pp. 3488-3494, 2012.

[66] E. J. T. Pialago, O. K. Kwon, and C. W. Park, "Nucleate boiling heat transfer of R134a on cold sprayed CNT-Cu composite coatings," Applied Thermal Engineering, vol. 56, no. 1-2, pp. 112-119, 2013.

[67] E. J. T. Pialago, O. K. Kwon, J. S. Jin, and C. W. Park, "Nucleate pool boiling of R134a on cold sprayed Cu-CNT-SiC and Cu-CNT-AlN composite coatings," Applied Thermal Engineering, vol. 103, pp. 684-694, 2016.

[68] E. J. Pialago, X. R. Zheng, K. A. Ada, et al., "A study on the effects of ceramic content of CNT/metal composite surface coatings fabricated by cold spray for boiling heat transfer enhancement," in Proceedings of the ASME 2012 3rd Micro/Nanoscale Heat \& Mass Transfer International Conference, Atlanta, GA, USA, 2012.

[69] D. Lin, C. Richard Liu, and G. J. Cheng, "Single-layer graphene oxide reinforced metal matrix composites by laser sintering: microstructure and mechanical property enhancement," Acta Materialia, vol. 80, pp. 183-193, 2014.

[70] L. Y. Chen, H. Konishi, A. Fehrenbacher et al., "Novel nanoprocessing route for bulk graphene nanoplatelets reinforced metal matrix nanocomposites," Scripta Materialia, vol. 67, no. 1, pp. 29-32, 2012.

[71] F. Chen, J. Ying, Y. Wang, S. Du, Z. Liu, and Q. Huang, "Effects of graphene content on the microstructure and properties of copper matrix composites," Carbon, vol. 96, pp. 836-842, 2016.

[72] W. Zhai, X. Shi, M. Wang et al., "Grain refinement: a mechanism for graphene nanoplatelets to reduce friction and wear of Ni3Al matrix self-lubricating composites," Wear, vol. 310, no. 1-2, pp. 33-40, 2014.

[73] Z. Xu, X. Shi, W. Zhai, J. Yao, S. Song, and Q. Zhang, "Preparation and tribological properties of TiAl matrix composites reinforced by multilayer graphene," Carbon, vol. 67, pp. 168-177, 2014.

[74] Y. Fan, L. Kang, W. Zhou, W. Jiang, L. Wang, and A. Kawasaki, "Control of doping by matrix in few-layer graphene/metal oxide composites with highly enhanced electrical conductivity," Carbon, vol. 81, pp. 83-90, 2015.

[75] X. Huang, X. Qi, F. Boey, and H. Zhang, "Graphene-based composites," Chemical Society Reviews, vol. 41, no. 2, pp. 666-686, 2012.

[76] J. Dutkiewicz, P. Ozga, W. Maziarz et al., "Microstructure and properties of bulk copper matrix composites strengthened with various kinds of graphene nanoplatelets," Materials Science and Engineering: A, vol. 628, pp. 124-134, 2015.

[77] S. Xu, X. Gao, M. Hu et al., "Dependence of atomic oxygen resistance and the tribological properties on microstructures of WS2 films," Applied Surface Science, vol. 298, pp. 36-43, 2014.

[78] A. Loganathan, S. Rengifo, A. F. Hernandez et al., "Effect of 2D WS2 addition on cold-sprayed aluminum coating," Journal of Thermal Spray Technology, vol. 26, no. 7, pp. 1585-1597, 2017.

[79] A. Rahbar-kelishami, A. Abdollah-zadeh, M. M. Hadavi, A. Banerji, A. Alpas, and A. P. Gerlich, "Effects of friction stir processing on wear properties of WC-12\%Co sprayed on 52100 steel," Materials and Design, vol. 86, pp. 98-104, 2015.

[80] C. J. Li and G. J. Yang, "Relationships between feedstock structure, particle parameter, coating deposition, microstructure and properties for thermally sprayed conventional 
and nanostructured WC-Co," International Journal of Refractory Metals and Hard Materials, vol. 39, pp. 2-17, 2013.

[81] S. Al-Mutairi, M. S. J. Hashmi, B. S. Yilbas, and J. Stokes, "Microstructural characterization of HVOF/plasma thermal spray of micro/nano WC-12\%Co powders," Surface and Coatings Technology, vol. 264, pp. 175-186, 2015.

[82] H. L. D. V. Lovelock, "Powder/processing/structure relationships in WC-Co thermal spray coatings: a review of the published literature," Journal of Thermal Spray Technology, vol. 7, no. 3, pp. 357-373, 1998.

[83] J. He and J. M. Schoenung, "A review on nanostructured WC-Co coatings," Surface and Coatings Technology, vol. 157, no. 1, pp. 72-79, 2002.

[84] S. Yin, E. J. Ekoi, T. L. Lupton, D. P. Dowling, and R. Lupoi, "Cold spraying of WC-Co-Ni coatings using porous WC17Co powders: formation mechanism, microstructure characterization and tribological performance," Materials and Design, vol. 126, pp. 305-313, 2017.

[85] K. Kumari, K. Anand, M. Bellacci, and M. Giannozzi, "Effect of microstructure on abrasive wear behavior of thermally sprayed WC-10Co-4Cr coatings," Wear, vol. 268, no. 11-12, pp. 1309-1319, 2010.

[86] A. A. Burkov and S. A. Pyachin, "Formation of WC-Co coating by a novel technique of electrospark granules deposition," Materials and Design, vol. 80, pp. 109-115, 2015.

[87] S. Dosta, G. Bolelli, A. Candeli, L. Lusvarghi, I. G. Cano, and J. M. Guilemany, "Plastic deformation phenomena during cold spray impact of WC-Co particles onto metal substrates," Acta Materialia, vol. 124, pp. 173-181, 2017.

[88] H.-J. Kim, C.-H. Lee, and S.-Y. Hwang, "Fabrication of WC-Co coatings by cold spray deposition," Surface and Coatings Technology, vol. 191, no. 2-3, pp. 335-340, 2005.

[89] H.-J. Kim, C.-H. Lee, and S.-Y. Hwang, "Superhard nano WC-12\%Co coating by cold spray deposition," Materials Science and Engineering: A, vol. 391, no. 1-2, pp. 243-248, 2005.

[90] M. Couto, S. Dosta, and J. M. Guilemany, "Comparison of the mechanical and electrochemical properties of WC-17 and 12Co coatings onto Al7075-T6 obtained by high velocity oxy-fuel and cold gas spraying," Surface and Coatings Technology, vol. 268, pp. 180-189, 2014.

[91] A. S. M. Ang, C. C. Berndt, and P. Cheang, "Deposition effects of WC particle size on cold sprayed WC-Co coatings," Surface and Coatings Technology, vol. 205, no. 10, pp. 3260-3267, 2011.

[92] M. Couto, S. Dosta, J. Fernández, and J. M. Guilemany, "Comparison of the mechanical and electrochemical properties of WC-25Co coatings obtained by high velocity oxyfuel and cold gas spraying," Journal of Thermal Spray Technology, vol. 23, no. 8, pp. 1251-1258, 2014.

[93] H.-T. Wang, X. Chen, X.-B. Bai, G.-C. Ji, Z.-X. Dong, and D.-L. Yi, "Microstructure and properties of cold sprayed multimodal WC-17Co deposits," International Journal of Refractory Metals and Hard Materials, vol. 45, pp. 196-203, 2014.

[94] G.-J. Yang, P.-H. Gao, C.-X. Li, and C.-J. Li, "Mechanical property and wear performance dependence on processing condition for cold-sprayed WC-(nanoWC-Co)," Applied Surface Science, vol. 332, pp. 80-88, 2015.

[95] Q. L. Che, J. J. Zhang, X. K. Chen et al., "Spark plasma sintering of titanium-coated diamond and copper-titanium powder to enhance thermal conductivity of diamond/copper composites," Materials Science in Semiconductor Processing, vol. 33, pp. 67-75, 2015.
[96] A. M. Abyzov, M. J. Kruszewski, Ł. Ciupiński, M. Mazurkiewicz, A. Michalski, and K. J. Kurzydłowski, "Diamond-tungsten based coating-copper composites with high thermal conductivity produced by pulse plasma sintering," Materials \& Design, vol. 76, pp. 97-109, 2015.

[97] W. Z. Shao, V. V. Ivanov, L. Zhen, Y. S. Cui, and Y. Wang, "A study on graphitization of diamond in copper-diamond composite materials," Materials Letters, vol. 58, no. 1-2, pp. 146-149, 2004.

[98] K. Chu, Z. Liu, C. Jia et al., "Thermal conductivity of SPS consolidated $\mathrm{Cu} /$ diamond composites with $\mathrm{Cr}$-coated diamond particles," Journal of Alloys and Compounds, vol. 490, no. 1-2, pp. 453-458, 2010.

[99] T. Schubert, Ł. Ciupiński, W. Zieliński, A. Michalski, T. Weißgärber, and B. Kieback, "Interfacial characterization of $\mathrm{Cu}$ /diamond composites prepared by powder metallurgy for heat sink applications," Scripta Materialia, vol. 58, no. 4, pp. 263-266, 2008.

[100] A. M. Abyzov, S. V. Kidalov, and F. M. Shakhov, "High thermal conductivity composite of diamond particles with tungsten coating in a copper matrix for heat sink application," Applied Thermal Engineering, vol. 48, pp. 72-80, 2012.

[101] H. Feng, J. K. Yu, and W. Tan, "Microstructure and thermal properties of diamond/aluminum composites with $\mathrm{TiC}$ coating on diamond particles," Materials Chemistry and Physics, vol. 124, no. 1, pp. 851-855, 2010.

[102] Q. Kang, X. He, S. Ren et al., "Preparation of copperdiamond composites with chromium carbide coatings on diamond particles for heat sink applications," Applied Thermal Engineering, vol. 60, no. 1-2, pp. 423-429, 2013.

[103] J. Li, H. Zhang, Y. Zhang, Z. Che, and X. Wang, "Microstructure and thermal conductivity of $\mathrm{Cu} /$ diamond composites with Ti-coated diamond particles produced by gas pressure infiltration," Journal of Alloys and Compounds, vol. 647, pp. 941-946, 2015.

[104] Y. Dong, R. Zhang, X. He, Z. Ye, and X. Qu, "Fabrication and infiltration kinetics analysis of Ti-coated diamond/copper composites with near-net-shape by pressureless infiltration," Materials Science and Engineering: B, vol. 177, no. 17, pp. 1524-1530, 2012.

[105] K. Venkateswarlu, A. K. Ray, M. K. Gunjan, D. P. Mondal, and L. C. Pathak, "Tribological wear behavior of diamond reinforced composite coating," Materials Science and Engineering: $A$, vol. 418, no. 1-2, pp. 357-363, 2006.

[106] A. F. Richardson, A. Neville, and J. I. B. Wilson, "Developing diamond MMCs to improve durability in aggressive abrasive conditions," Wear, vol. 255, no. 1-6, pp. 593-605, 2003.

[107] K. Venkateswarlu, V. Rajinikanth, T. Naveen, D. P. Sinha, Atiquzzaman, and A. K. Ray, "Abrasive wear behavior of thermally sprayed diamond reinforced composite coating deposited with both oxy-acetylene and HVOF techniques," Wear, vol. 266, no. 9-10, pp. 995-1002, 2009.

[108] L. Yang, B. Li, J. Yao, and Z. Li, "Effects of diamond size on the deposition characteristic and tribological behavior of diamond/Ni60 composite coating prepared by supersonic laser deposition," Diamond and Related Materials, vol. 58, pp. 139-148, 2015.

[109] J. Yao, L. Yang, B. Li, and Z. Li, "Beneficial effects of laser irradiation on the deposition process of diamond/Ni60 composite coating with cold spray," Applied Surface Science, vol. 330, pp. 300-308, 2015.

[110] S. Yin, Y. Xie, J. Cizek et al., "Advanced diamond-reinforced metal matrix composites via cold spray: properties and 
deposition mechanism," Composites Part B: Engineering, vol. 113, pp. 44-54, 2017.

[111] Y. Xie, S. Yin, C. Chen, M. Planche, H. Liao, and R. Lupoi, "New insights into the coating/substrate interfacial bonding mechanism in cold spray," Scripta Materialia, vol. 125, pp. 1-4, 2016.

[112] W. J. Zhang, Y. M. Chong, I. Bello, and S. T. Lee, "Nucleation, growth and characterization of cubic boron nitride (cBN) films," Journal of Physics D: Applied Physics, vol. 40, no. 20, pp. 6159-6174, 2007. 


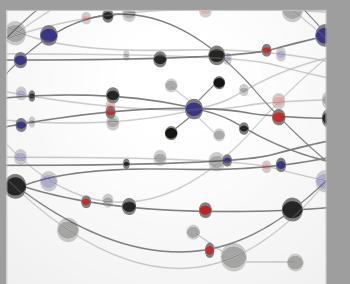

The Scientific World Journal
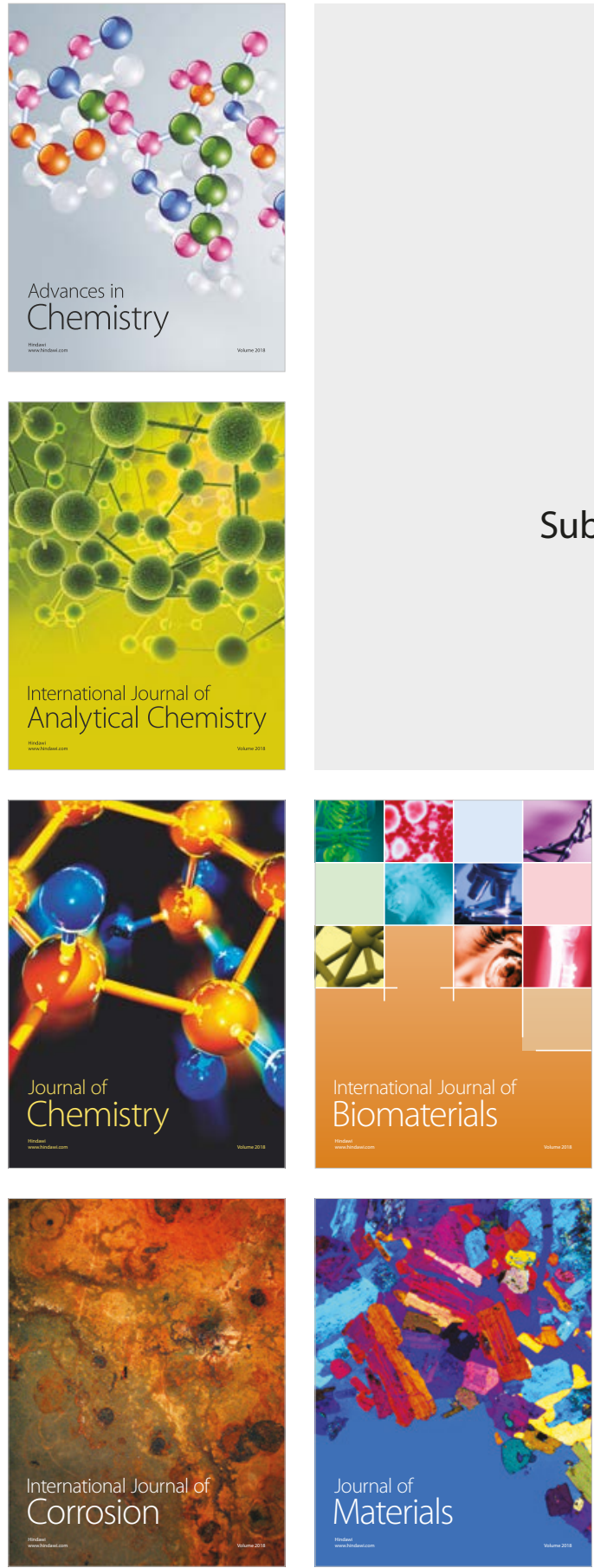

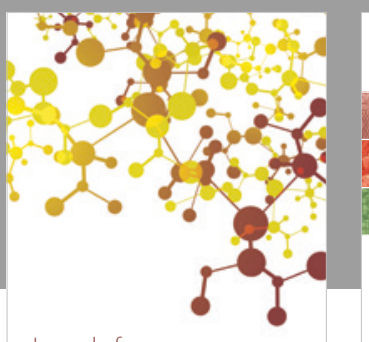

Journal of

Applied Chemistry
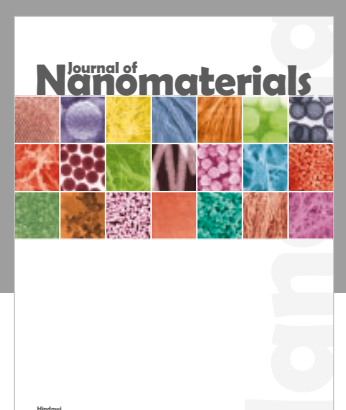

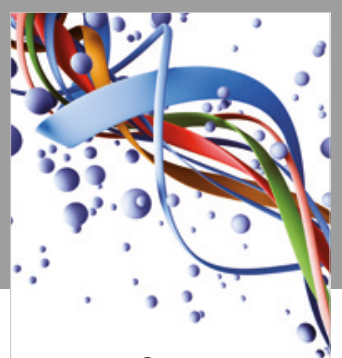

Scientifica

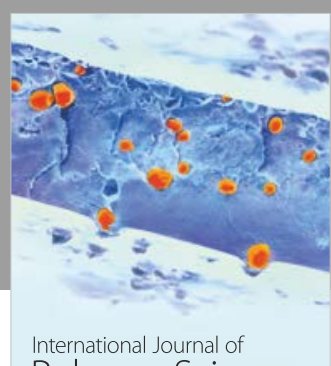

Polymer Science

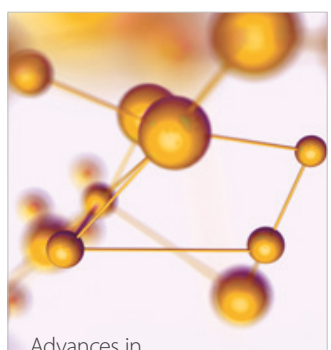

Physical Chemistry
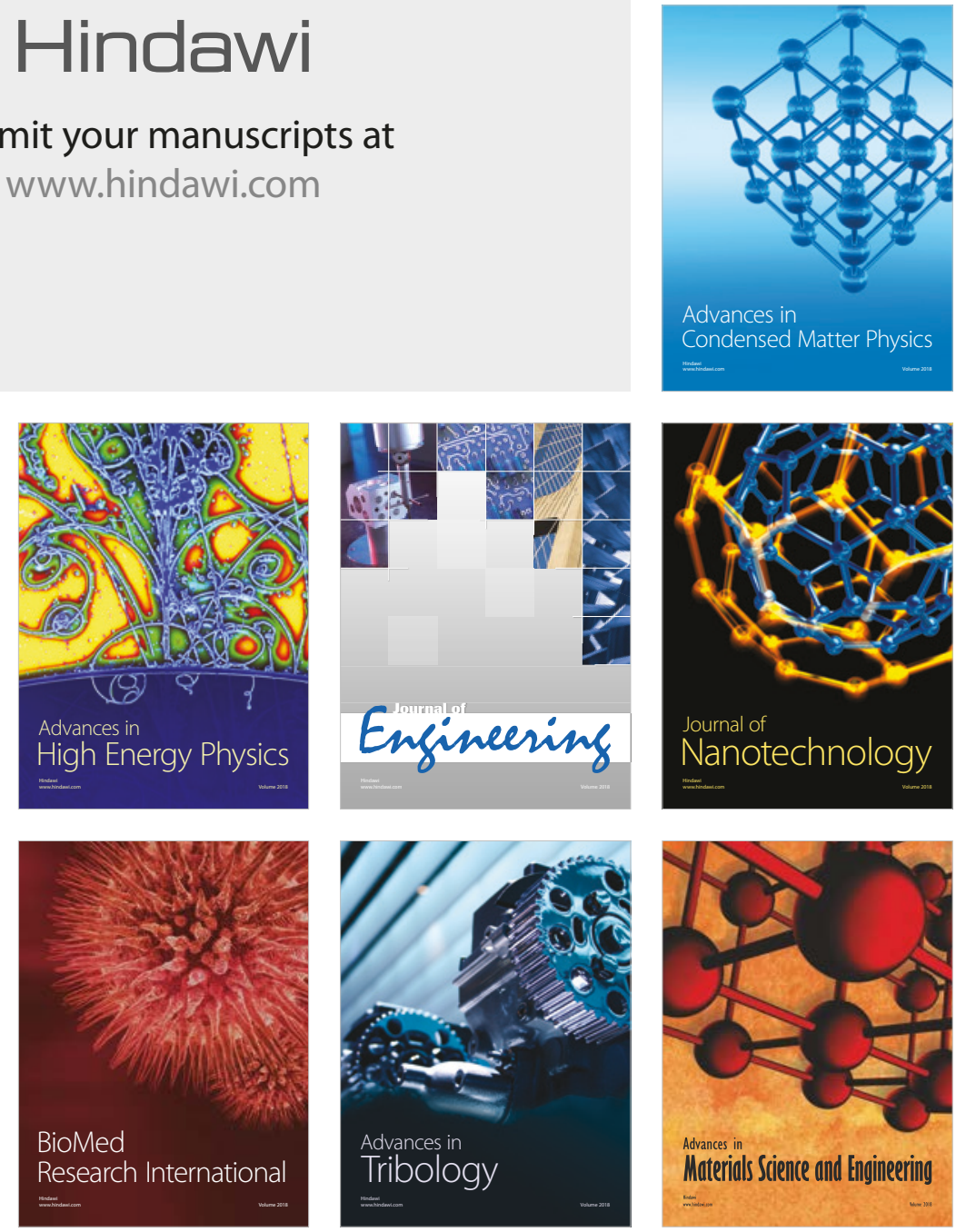